\title{
EL FONDEADERO DE LA PLATJA DE LA VILA (LA VILA JOIOSA, ALICANTE): LA ÉPOCA CLÁSICA
}

\author{
ANTONIO ESPINOSA RUIZ \\ Universidad de Alicante \\ FERNANDO SÁEZ LARA \\ ROCÍO CASTILLO BELINCHÓN
}

\begin{abstract}
El fondeadero de la Platja de la Vila presenta una utilización continuada al menos entre los siglos II a.C. y V d.C., y a partir del s. XIV hasta los años veinte del presente. Estudiamos aquí los materiales de época clásica, obtenidos durante los trabajos de prospección subacuática desarrollados por nuestro equipo, a los que se añade las piezas extraidas por el club de buceo local. Se presta una especial atención a la interrelación con el contexto arqueológico de tierra.

Le mouillage de la Platja de la Vila présente une utilisation continue, tout au moins, entre le II me s. av. J-C et le $V^{\text {inc }} 5$ ap. J-C, et a partir du XIV ène s. jusqu'aux années 20 du présent. On étudie dans cet article-ci les matériaux d'époque classique qui ont été obtenus pendant les travaux de prospection dévéloppés par notre équipe, mais aussi les pieces tirées de la mer par le club local de plongée. On a fait une attention spéciale à la relation avec le contexte archélogique de terre.
\end{abstract}

El fondeadero de la Platja («playa») de la Vila es uno de los lugares estudiados dentro del Inventario de yacimientos arqueológicos sumergidos del litoral de la provincia de Alicante ${ }^{\perp}$ Ha de entenderse este proyecto como una «carta arqueológica» en su acepción más amplia, con especial atención a la interrelación con la Arqueología de tierra².

\section{SITUACIÓN Y MEDIO GEOGRÁFICO}

Las coordenadas U.T.M. de la zona nuclear del yacimien- to son 30SYH419654. Corresponde a las hojas cartográficas siguientes: 847 del Mapa Topográfico de España del I.G.C.

\footnotetext{
'Para un análisis pormenorizado de las características del proyecto, véase ESPINOSA y SÁEZ (e.p. 1 y e.p. 2). Las memorias científicas correspondientes $(1989,1990$ y 1991) se encuentran depositadas en Dirección General de Patrimonio Artístico de la Consellería de Cultura de la Generalitat Valenciana.

${ }^{2}$ Hasta el momento se han realizado tres campañas ordinarias sub-
} 


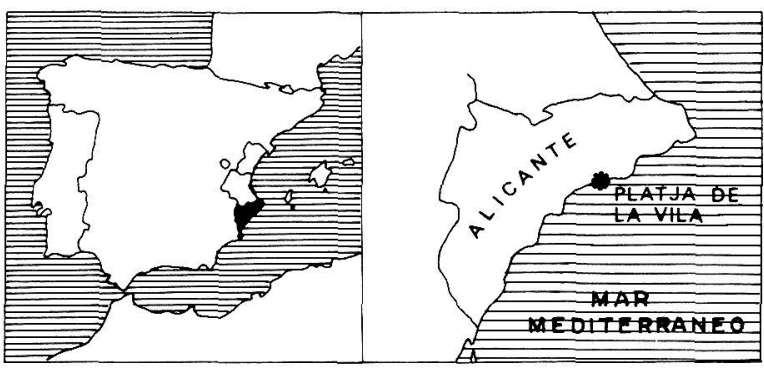

Fig. 1.- Mapa de situación.

(E. 1:50.000); 833 (E. 1:98.500) y 729 (E. 1:9.450) de la Carta Náutica de las Costas de España.

El relieve de la comarca pertenece al Prebético Interno (COLODRÓN, RUIZ y NÚÑEZ, 1981, 17). El costero, predominantemente terciario, es bastante accidentado, con alternancia de acantilados y playas. La mitad meridional de la comarca de la Marina Baixa, en la que se inscribe la ensenada de la Vila Joiosa, y dentro de ella el fondeadero que nos ocupa, presenta un talud litoral característico, de alrededor de veinte metros de desnivel mínimo, perteneciente al denominado surco de flysch Campello-Villajoyosa. Esta unidad geológica está formada por materiales poco compactos, paleógenos y de comienzos del Mioceno (sucesiones de margas arcillosas, areniscas y calizas fosilíferas). Las bajadas naturales hacia la costa son escasas, y en la ensenada de la Vila Joiosa se relacionan con los cauces del río de la Vila (o Amadorio) y del desaparecido Barranquet (fig. 4). Alrededor de esta ensenada se dispone una amplia y fértil llanura litoral, formada por sedimentos pleistocénicos aluviales que quedan retenidos en las ligeras elevaciones costeras.

El fondeadero está situado frente a una playa arenosa, sin abrigo natural. No obstante, en el extremo oriental de la misma ensenada de La Vila, se encontraba el reducido abrigo de l'Alcocó, con un manantial de agua dulce, que ofrecía cierta protección de los vientos del $1 .^{\circ}$ y $4 .^{\circ}$ cuadrantes-NW, N y NE-y una total abertura al leveche y poniente (SW y W). El litoral alicantino, muy poco articulado en general, ofrece tan sólo algunos mediocres abrigos naturales para la navegación, entre los cuales no destaca el de Alcocó (ROSSELLO, 1978, 21).

Los fondos de la Platja de la Vila ofrecen una pendiente muy suave: el veril $-5 \mathrm{~m}$. se sitúa a unos $150 \mathrm{~m}$. de la línea de costa. Una superficie arenosa desnuda caracteriza el espacio comprendido entre las isobatas 0 y $-4 \mathrm{~m}$. A partir de aquí domina la pradera de Posidonia oceánica (fig. 3). Esta puede desarrollarse en dirección vertical, formando gruesos mantos de rizomas (GARCÍA, SILVESTRE y PÉREZ, 1989, 622623), que en nuestro caso alcanzan una media de 1,5-2 m. de altura. Tal fenómeno ha producido una auténtica estratigrafía natural de gran interés arqueológico, al tiempo que hace prác-

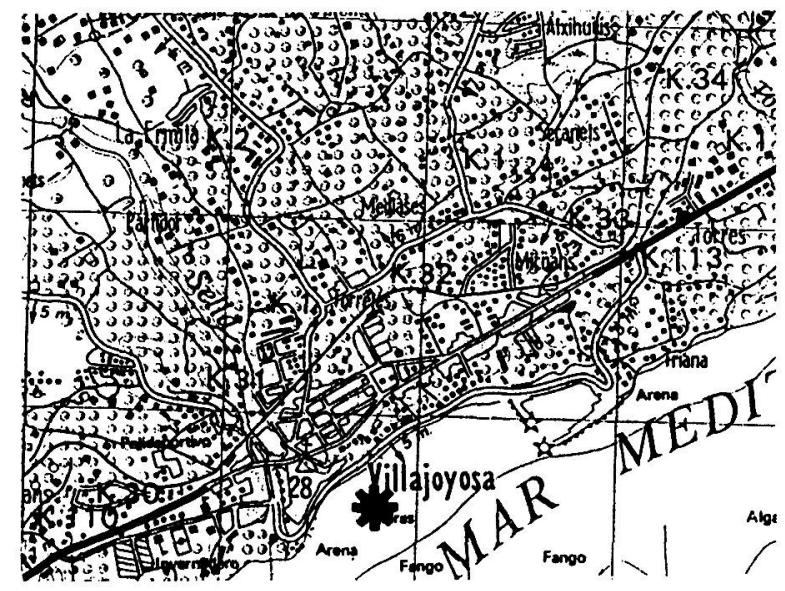

Fig. 2.- Mapa de situación, E:50.000.

ticamente imposible encontrar sobre la pradera materiales de época clásica, que por el contrario afloran al pie de los taludes de los frentes de erosión, asociados a claros de fondo arenoso.

\section{CONTEXTO ARQUEOLÓGICO}

El poblamiento ibérico y romano, abundante en toda la comarca, es especialmente denso en esta llanura litoral de la Vila Joiosa, como se ha puesto de relieve en algunos trabajos recientes ${ }^{3}$. En ella hay que buscar el municipium del que tenemos noticias por la epigrafía, cuyo nombre nos es todavía desconocido $^{4}$, y que alcanzó probablemente la categoría municipal en época Flavia, presumiblemente como consecuencia de

vencionadas por la Generalitat Valenciana $(1989,1990$ y 1991) y Ministerio de Cultura (1989), durante parte de las cuales se trabajó en la Platja de la Vila. Se encuentra en preparación un artículo sobre los materiales de épocas medieval y moderna, a excepción de las anclas líticas (publicadas en CAÑADAS, CASTILLO, ESPINOSA y SÁEZ, e.p.

Cf. ESPINOSA, 1989; 1990, e.p. 2. Puede consultarse, como visión de conjunto más reciente, la Memoria de Licenciatura de A. Espinosa, titulada Arqueología romana de la Vila Joiosa, bajo la dirección de la Dra. C. Fernández Ochoa, leída en el Departamento de Prehistoria y Arqueología de la Universidad Autónoma de Madrid con fecha 1 de octubre de 1990. Sobre recientes intervenciones ordinarias y de salvamento existe ya una numerosa bibliografía tanto científica (ESPINOSA, e.p. 2; OLCINA, 1990a y 1990b) como divulgativa (remitimos a ESPINOSA, e.p. 2, con completa bibliografía de carácter local).

${ }^{4}$ Sobre los hallazgos epigráficos y el problema de la ubicación de la ciudad romana consúltese: ESPINOSA, 1989; 1993 e.p. 2, ABAD, 1985; RABANAL y ABASCAL 1985, 217-223, 1986, ABAD y ABASCAL, 1991, 52 y 116-125, OLCINA, 1990, 181-183, así como la Memoria de Licenciatura de A. Espinosa (vid. nota 3). 


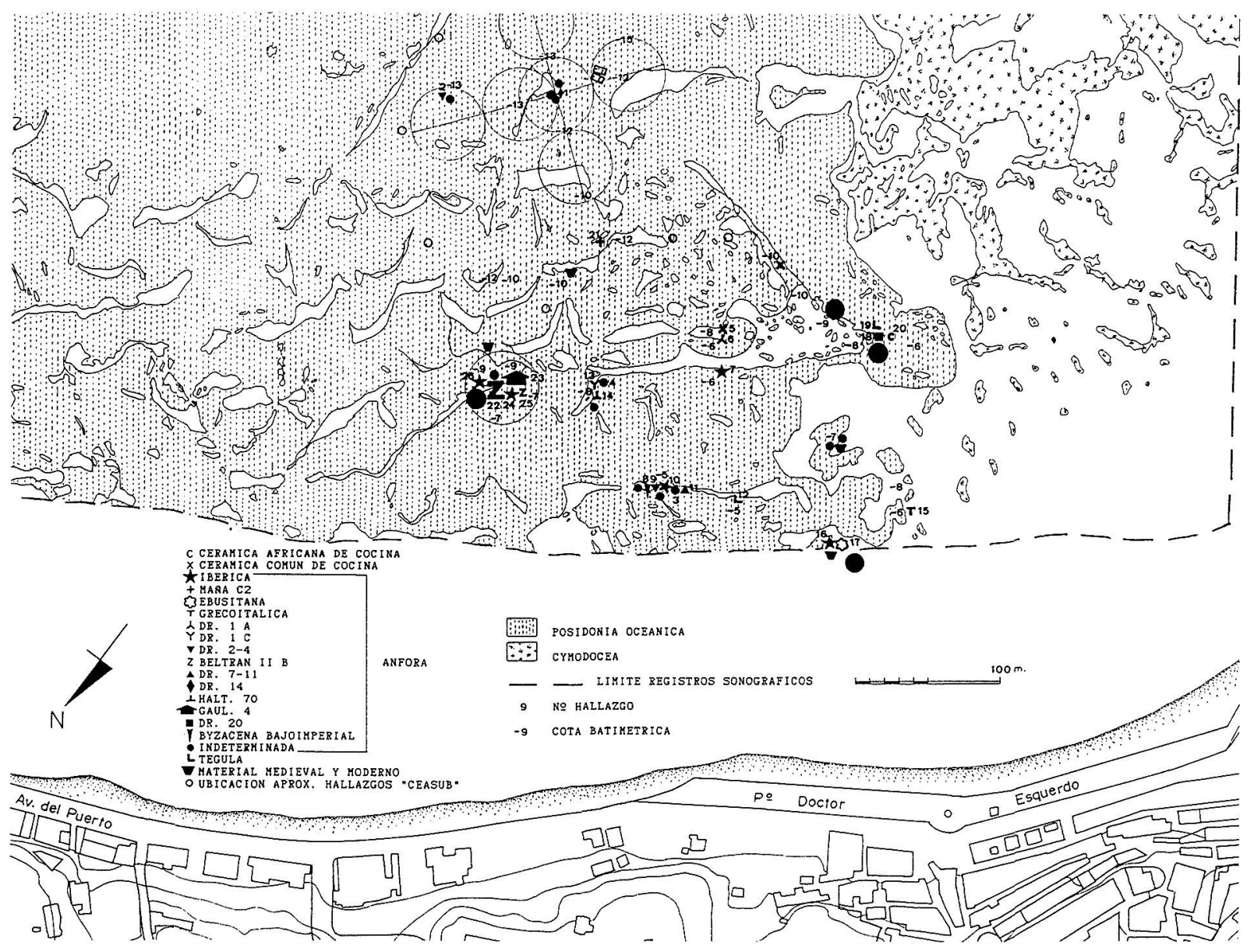

Fig. 3.- Plano del yacimiento. Los símbolos grandes indican mas de dos piezas del mismo tipo.

un período de crecimiento importante. Este pudo originarse bajo el reinado de Augusto y alcanzar su punto álgido en el siglo II, tal y como demuestran, entre otros hechos, la erección de la torre de S. José (ABAD y BENDALA, 1985) o la restauración y mejora del macellum local, testimonios de cierta monumentalización.

Dentro del poblamiento romano de la Marina Baixa cabe destacar un nutrido conjunto de noticias, hallazgos fortuitos y excavaciones de salvamento que demuestran la existencia de un importante núcleo de población (probablemente el propio municipium) bajo una parte del actual casco urbano de la Vila Joiosa. Conocemos una de sus necrópolis (ESPINOSA, 1989; 1990; 1993) y un área de almacenaje (hallazgo casual de una serie de dolia) en la Plaça de S. Pere, a pie de costa, dentro de la propia Platja de la Vila, así como un poblado de la Primera y Segunda Epocas Ibéricas bajo el casco antiguo de la ciudad (ESPINOSA, e.p.2) $)^{5}$, que constituye un claro precedente del núcleo romano (fig 4).

\section{METODOLOGÍA Y DESARROLLO DEL TRABAJO DE CAMPO 6}

Podemos diferenciar dos grupos principales de técnicas de prospección: la observación visual directa y la utilización de la geofísica. El rastreo visual obedeció, durante la primera

\footnotetext{
${ }^{5}$ Sobre el poblamiento ibérico de la comarca remitimos a un próximo trabajo de conjunto que se encuentra en fase de realización por A. Espinosa. Respecto al poblado ibérico del casco antiguo de la Vila Joiosa ya encontramos una mención en la obra de LLOBREGAT, 1972, 110.

'No ofreceremos aquí la larga lista de personas e instituciones a las que nuestro Proyecto debe gratitud su colaboración en distintos aspectos del desarrollo de los trabajos (puede verse en ESPINOSA y SÁEZ, e.p. 2). Por lo que respecta a las prospecciones en la Platja de la Vila no queremos eludir una mención al decidido apoyo del Ayuntamiento de la ciudad, Club Náutico y Ayudantía de Marina y a la colaboración del club de buceo local CEASUB.
} 


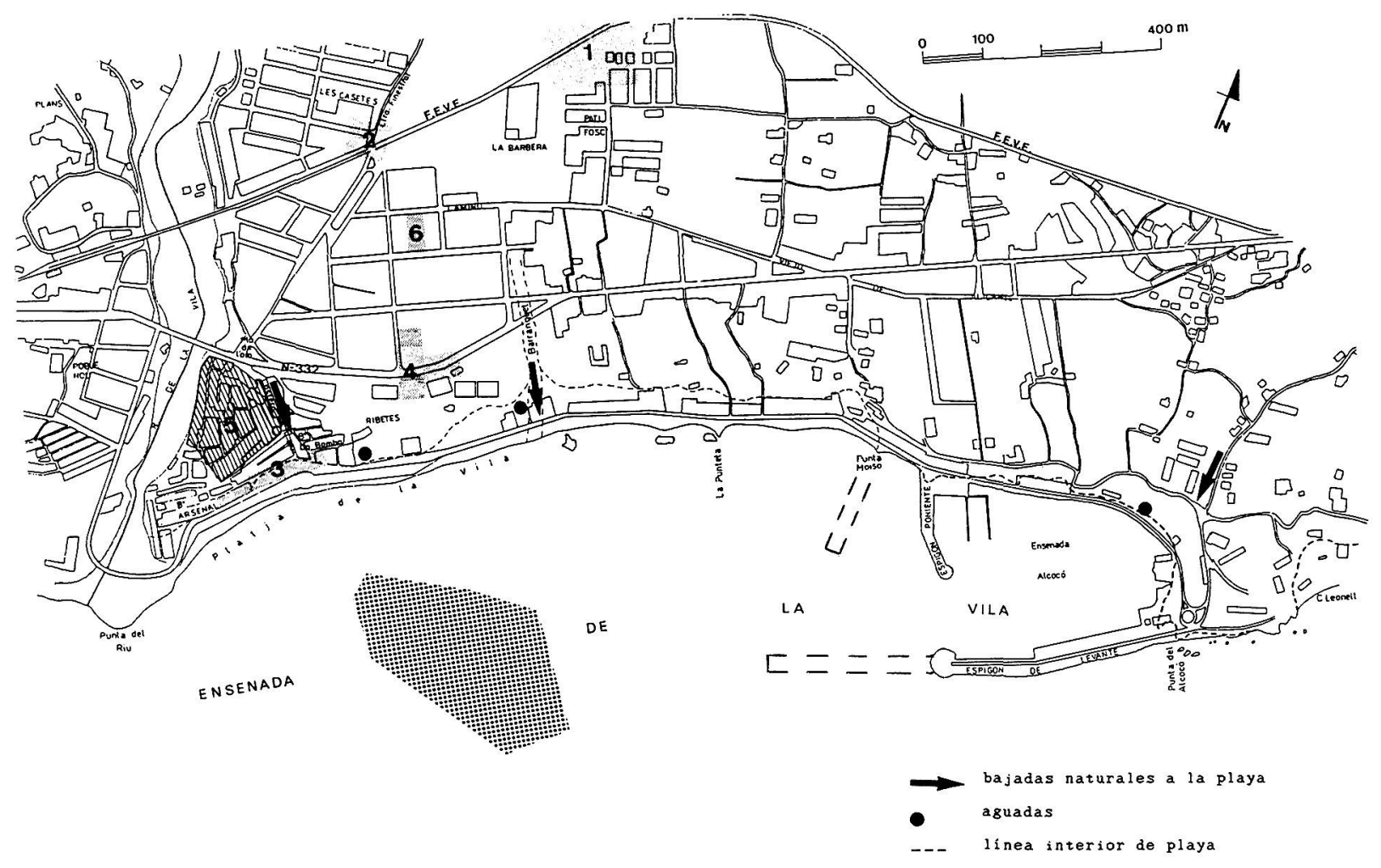

Fig. 4.- Plano del contexto geográfico y arqueológico. La trama de puntos indica la extensión conocida del fondeadero hasta 1991; la trama gris marca la de los yacimientos de época romana próximos a la ensenada de la Vila: 1. La Jovada-La Barbera (materiales s. I-V d.C.). 2. necrópolis Casetes (al menos s. I-III d.C.); 3. Plaça de Sant Pere (probable almacén portuario romano, cronol. indet.); 4. Ribetes (bajoimperial); 5. Casco antiguo (recinto amurallado medieval y moderno y poblado del Ibérico Pleno y Final, o Primera y Segunda Épocas Ibéricas); 6. Ramón y Cajal, 10 (habitat, s. II a.C.-I

fase, a distintos criterios: seguimiento de cotas batimétricas, ejes perpendiculares y paralelos a la línea de costa, ejes cartesianos siguiendo orientaciones cardinales, etc. Finalmente se decidió prospectar con mayor intensidad las unidades topográficas significativas: los taludes correspondientes a los frentes de erosión antes mencionados. Unicamente ahí era posible detectar material arqueológico anterior a la época moderna. Estos taludes se concentran en la banda limitada por los veriles -5 y -16 m., aproximadamente. Para su seguimiento exhaustivo era necesario algún tipo de cartografía topográfica detallada del fondo, sólo obtenible mediante la utilización del sonar de barrido lateral'. Ello fue posible gracias a un Convenio entre

\footnotetext{
${ }^{7}$ Véase algunos ejemplos de aplicación del sonar de barrido lateral a la Arqueología en MACEL (1985), MITCHELL (1985), PEARSON (1982) y THEURET (1980). El modelo de sonar utilizado es el Klein 595-100 KHz. Se realizaron recorridos paralelos distanciados entre sí $25 \mathrm{~m}$., y con una banda de prospección de esta misma anchura a cada lado de la embarcación, lo que permitió el solapamiento de
}

la Consellería de Cultura, Educación y Ciencia y el Centro Nacional de Investigaciones Arqueológicas Subacuáticas, que puso a nuestra disposición la embarcación LIPS dotada de sistemas de prospección geofísica y dos técnicos especialistas ${ }^{8}$. En este caso no se trataba de utilizar el sonar tanto para locali-

la mitad longitudinal de cada línea con la anterior. El posicionamiento por triangulación mediante dos teodolitos presenta un escaso margen de error $(5 \mathrm{~cm}$. sobre $100 \mathrm{~m}$. de distancia, aunque esta cifra debe incrementarse ligeramente, teniendo en cuenta que la embarcación se desplazaba a 3 nudos de velocidad). Las alternativas a este sistema convencional, más cómodas (posicionamiento por satélite o mediante distanciómetro y planimetría asistida por ordenador), no se encontraban disponibles en instancias oficiales en aquel momento, y la contratación de una empresa privada escapaba a las posibilidades de nuestro presupuesto. La utilización de dos teodolitos venía avalada, en cualquier caso, por proyectos anteriores (véase MITCHELL, 1985 y NIETO, 1984, 46).

${ }^{8}$ Queremos agradecer a D." Paloma Cabrera, entonces directora del C.N.I.A.S., su interés por la consecución del Convenio, y a los téc- 


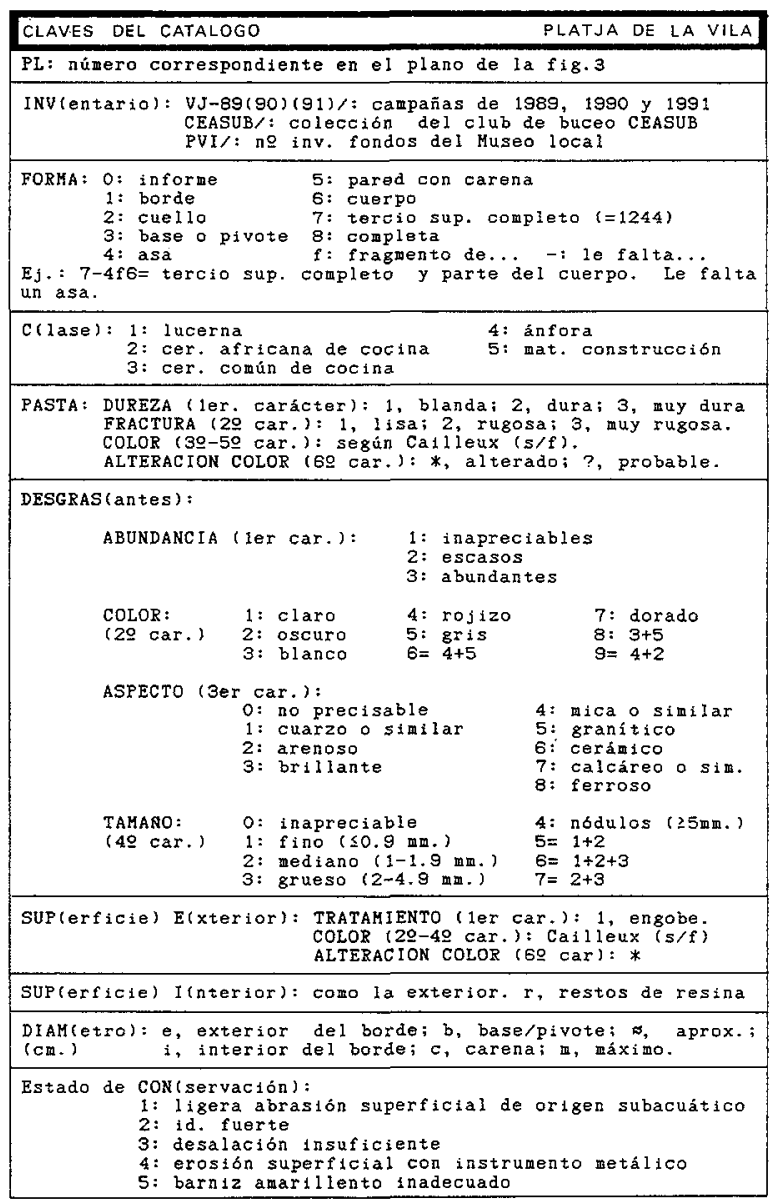

Tabla 1.-

zar restos—sin desechar esta posibilidad—cuanto de obtener un mapa con el que trabajar en el fondo y sobre el que superponer los hallazgos, localizados siempre mediante teodolitos (fig. 3). De esta forma se obtuvo un mapa que permitió planificar previamente las inmersiones con un conocimiento pormenorizado del tipo de fondo, y evitar la prospección superficial de la lengua de sedimentación arenosa del río de la Vila, estéril desde el punto de vista arqueológico, entre otras ventajas.

Puntualmente, y por distintas razones, se empleó otro método de prospección visual, mediante círculos, con centro situado a partir de ejes aproximadamente paralelos y perpen-

nicos D. Mercedes Gómez y D. Roberto Ontañón, y al patrón de la embarcación, D. Emilio Pañuelas, el buen trabajo que llevaron a cabo durante la prospeccción. El Museo Arqueológico Provincial de Alicante colaboró mediante la cesión de uno de los teodolitos.

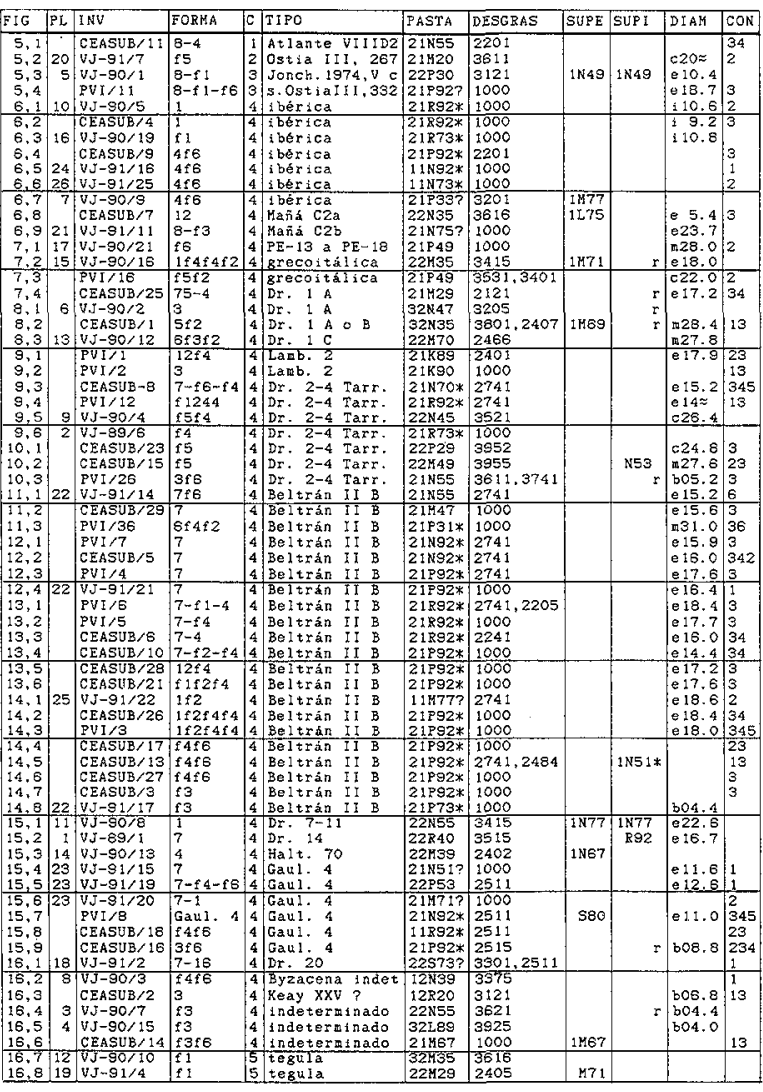

Tabla 2.- Catálogo de materiales.

diculares a la línea de costa (es decir, NW-SE, o eje de abscisas, y NE-SW, de ordenadas) (fig. 3).

\section{NOTAS SOBRE EL CATÁLOGO Y LAS ILUSTRACIONES}

Por razones prácticas presentamos el catálogo en forma de ficha, junto a las claves para su lectura ${ }^{9}$ (tablas 1 y 2 ). Las piezas están depositadas en distintos lugares: VJ-89(90)(91)/n en el Museo Arqueológico Provincial de Alicante ${ }^{\mathrm{in}} ; \mathrm{J}$ CEASUB $/ \mathrm{n}$

"Utilizamos las clasificaciones «tradicionales» del material anfórico, con sus abundantes correcciones, ampliaciones y novedades, porque opinamos que es ésta la mejor vía para el acercamiento al problema de la tipología. No creemos que soluciones como la utilización exclusiva de nuevas nomenclaturas generales, como la propuesta en el catálogo de Peacock y Williams (1986), para la clasificación tipológica, sirvan para clarificar el panorama, sino más bien al contrario (una discusión sobre la moda de la utilización del catálogo de Peacock y Williams como tipología en ALARCAO y MAYET, eds., 1990, 65-66).

${ }^{10}$ Agradecemos a este Museo el préstamo de los materiales durante el tiempo necesario para su estudio. 

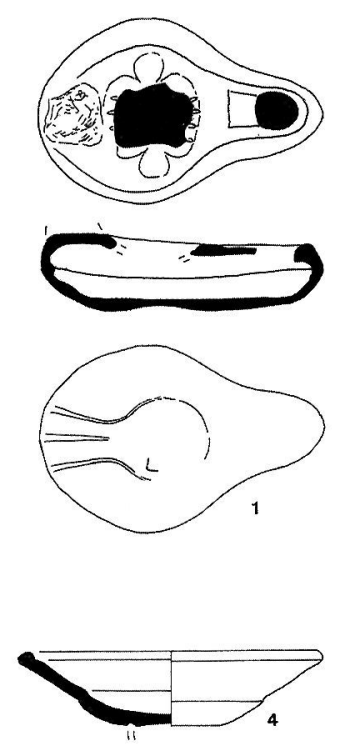

5
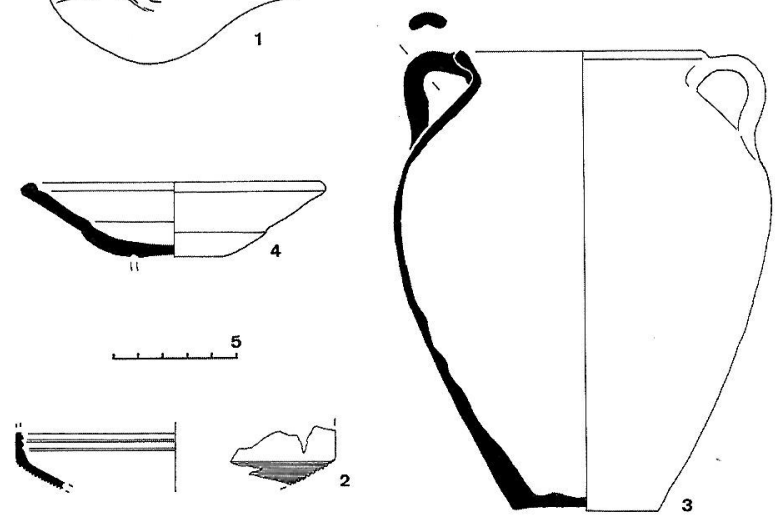

Fig. 5.-

en la colección del club de buceo local CEASUB; PVI/n proceden de donaciones al Museo local, por parte principalmente del citado club (excepto PVI/11, 12 y 26). Se incluye en el catálogo las que dan alguna forma, mientras las piezas informes serán objeto de un análisis detenido en el futuro, con el fin de extraer la mayor cantidad de información posible de las mismas. La dificultad de su estudio y la necesidad de establecer un criterio de selección que diera validez a las estadísticas nos han aconsejado no incluirlas aquí. Hemos de apuntar que, en el caso de los materiales extraidos por el club CEASUB, desconocemos las circunstancias y localización exacta de su hallazgo, lo que impide tener en cuenta estos factores a la hora de calcular el número mínimo de individuos.

Los colores de las pastas se expresan con las abreviaturas de CAILLEUX (slf)". Las descripciones se basan en la obser-

" Los códigos CAILLEUX registrados se corresponden con los siguientes nombres (según VV.AA. 1983) y abreviaturas del código MUNSELL: $\mathrm{K} 89=$ ocre amarillo claro $=2,5$ Y $9 / 6 ; \mathrm{K} 90=$ ocre amarillo claro=2'5 YR 8/3; L75= amarillo pálido= 10 YR 8/4; L89= amarillo pálido $=5$ Y 8/4; $\mathrm{M} 20=$ rosa $=5$ YR 7/6; M29= gris rosa $=$ YR 7/2; M35= tierra verde tostada= 5 YR 7/4; M39= tierra siena

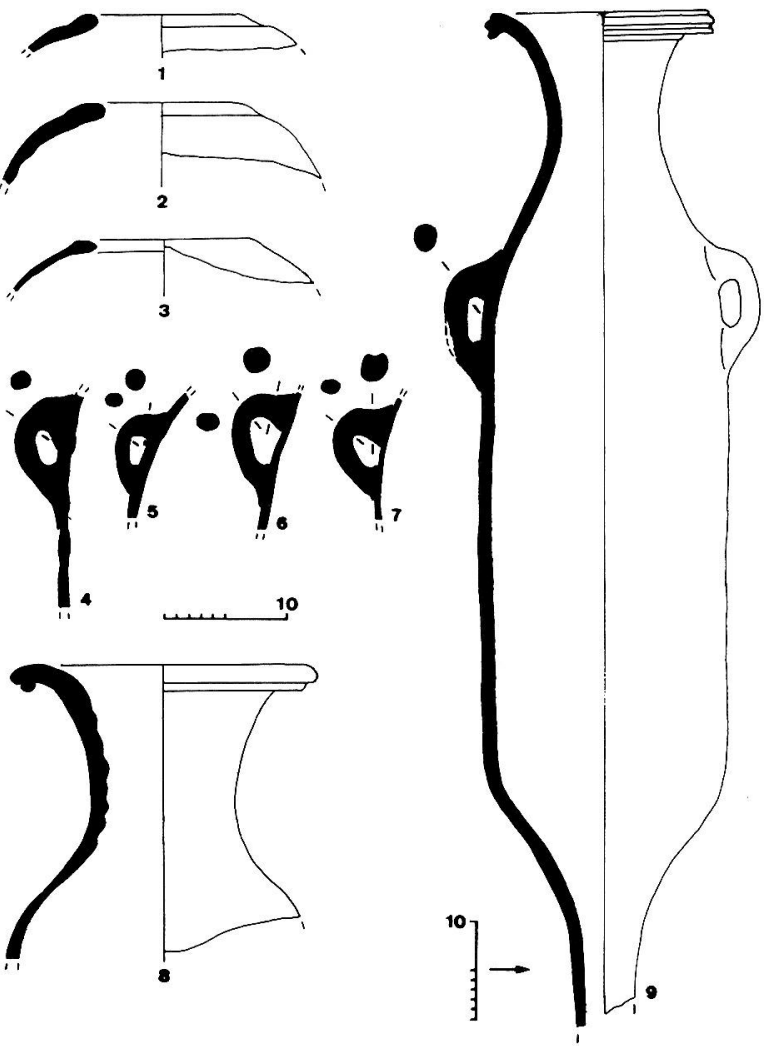

Fig. 6.-

vación visual con lupa de 4 aumentos, a la espera de los análisis de pastas, en proceso de realización. Los dibujos se ha realizado directamente sobre las piezas.

\section{ESTUDIO DE LOS MATERIALES ${ }^{12}$}

\section{Lucernas}

Atlante VIII D2 (probable). La superficie de nuestra pieza se encuentra bastante erosionada, pero es muy probable

tostada $=2$ ' 5 YR 6/8; M47= tierra verde tostada=2'5 YR 6/4; M49= tierra verde tostada $=5$ YR 7/4; M67, M69 y M70= pardo muy pálido=7'5 YR 7/4; M71= pardo pálido= 10 YR 7/4; M77= amarillo pálido=2'5 Y 7/4; N35= tierra siena tostada clara $=5$ YR 6/3; N39= tierra siena natural clara $=2$ '5 YR 6/8; N45 $=$ ocre carne $=5$ YR 6/6; $\mathrm{N} 47=$ tierra siena tostada $=2,5 \mathrm{YR} 5 / 6 ; \mathrm{N} 49=$ tierra verde tostada= $5 \mathrm{YR} 6 / 4 ; \mathrm{N} 51=$ tierra verde tostada $=5 \mathrm{YR} 6 / 2 ; \mathrm{N} 53=$ tierra verde tostada $=7$ '5 YR 6/2; N55= tierra siena natural= 5 YR 6/4; N67= Ocre $=7 ' 5$ YR $6 / 4 ; N 70=$ gris pardo claro $=7 ' 5$ YR $6 / 2 ; N 73=$ gris $=$ 2'5 Y 6/0; N77 ocre $=10$ YR $6 / 6 ; N 92=$ gris pardo claro $=5$ Y $6 / 1$; $\mathrm{P} 29=$ tierra de sombra tostada $=5 \mathrm{YR} 5 / 3 ; \mathrm{P} 30=$ gris rojo $=7 ' 5 \mathrm{YR}$ 5/2; P31 = gris= 7' 5 YR 5/0; P33= ocre oro tostado= 5 YR 5/3; P49= tierra siena tostada $=5$ YR $5 / 4 ; P 53=$ tierra verde tostada $=5$ YR 5/2; $\mathrm{P} 73=$ gris $=2,5 \mathrm{YR} 5 / 0 ; \mathrm{P} 92=$ pardo pardo $=5 \mathrm{Y} 5 / 1 ; \mathrm{R} 20=$ rojo inglés $=2$ ' 5 YR 4/6; $R 40=$ tierra siena $=2$ ' 5 YR 4/6; $R 73=$ gris oscu- 
la identificación con este tipo norteafricano de cerámica común (DENEAUVE, 1974, fig. 14, n. ${ }^{\circ}$ 43; PAVOLINI, 1981, 195, figs. XCVIII, 2 y CLVIII, 7a-b), de la segunda mitad del s. V. La superficie del rostrum está ennegrecida por el uso.

\section{Cerámica africana de cocina}

Ostia III, fig. 267 (Hayes 197). Este cuenco de origen tunecino tiene una dilatada cronología, entre el s. II y finales del IV-comienzos del V d.C. (HAYES, 1972; TORTORELLA, 1981, 218-219, fig. CVII, 6-7).

\section{Cerámica común de cocina}

Joncheray, 1974, $V$ c. Un paralelo idéntico a nuestra pieza en el pecio Drammont D (JONCHERAY, 1974, 38-40), datado entre 40 y 50 d.C. por la terra sigillata itálica. El mismo autor indica la aparición de esta forma cerámica de tradición itálica en yacimientos de épocas próximas a la señalada, por lo que podemos pensar en una datación probable del s. I d.C., con las lógicas reservas, dada la gran perduración de los tipos de la cerámica común.

Similis Ostia III, fig. 332. Este plato, de fabricación quizá regional (por el tipo de pasta), imita probablemente formas de la cerámica africana de cocina, y concretamente la propuesta (o una variante de la misma), datada en el s. II d.C. (TORTORELLA, 1981, 212).

\section{4. Ánforas}

Ibéricas. Su estudio es complicado principalmente por la falta de «estandarización». Aparte de la clasificación de Mañá (1950, tipo B 3) y de la de Almagro (1953, 398-399), aquélla demasiado genérica y ésta carente de fundamento cronológico, la primera sistematización de ánforas ibéricas es la elaborada por Pellicer para el valle del Guadalquivir (PELLICER, 1978 y 1982), partiendo de la excavación del Cerro Macareno (PELLICER, ESCACENA y BENDALA, 1983). Para la zona valenciana contamos con la tipología de A. Ribera (1982) y para la subibérica (desde el valle del Guadiana hasta el del Vinalopó) con la de C. Florido (1984). Sobre los hallazgos catalanes existe una síntesis de J. Miró (1984).

Las pastas de nuestras piezas son bastante homogéneas, depuradas, no muy duras y de fractura bastante rectilínea. $\mathrm{Su}$ color está por lo general alterado por procesos químicos desarrollados durante su larga permanencia en el fondo, que ha provocado unas tonalidades pardo-grisáceas (a veces oscuras), con la excepción de 6,7, que conserva probablemente su color

$\mathrm{ro}=2 ' 5$ Y $5 / 0 ; \mathrm{R} 92=$ gris oscuro $=5$ Y $5 / 1 ; \mathrm{S} 73=$ gris muy oscuro $=$ $2 ' 5$ Y $4 / 0$.

${ }^{12}$ En adelante nos referiremos a las piezas por su número de ilustración: así, 7,2 es la pieza $n{ }^{\circ} 2$ de la figura 7 . original ocre oro tostado ${ }^{13}$. Estas pastas pueden considerarse regionales (es decir, valencianas) ${ }^{14}$, aunque no estamos en condiciones de determinar si son locales.

Por lo que respecta a los bordes, las distintas variantes no parecen tener un significado cronológico claro (RIBERA, 1982, 122; MATA, 1991, 56) \% $^{15}$ Nuestros ejemplares muestran una cierta homogeneidad formal: son entrantes, planos, ligeramente engrosados, y formarían parte de ánforas sin cuello y sin solución de continuidad entre hombro y panza. Se corresponden con el tipo 4 de Pellicer (1978, fig. 7, D; id., 1983, fig. 86, D), datado entre mediados del s. III y el s. I a.C.; con el tipo XI de Florido (1984), cuya cronología va desde el s. IV a finales del s. II o principios del I a.C.; y con los tipos I-3 e I-5 de Ribera (1982, fig. 35), encuadrados respectivamente en los siglos IV-III a.C.y desde finales del III al I a.C. ${ }^{\text {I6 }}$. De los paralelos más estrechos puede deducirse un marco ubicable, con mayor probabilidad, en los siglos II y I a.C. ${ }^{17}$ (propio del tipo I-5 de Ribera), aunque no puede descartarse una fecha anterior, del s. III o incluso IV a.C. En cuanto a las asas, son dos los elementos que pueden tener un significado cronológico: su sección y su disposición. Todas ellas tienen sección circular (la excepción la constituye 6,7 , con acanaladura longitudinal en su parte superior), pero ésta podría deberse a la abrasión marina en 6,5 y 6,6 . La dificultad de orientación de los dibujos y las reducidas dimensiones de los fragmentos impiden encuadrarlos en uno de los dos grupos establecidos por A. Ribera (1982, 122). Todos estos factores limitan la formulación de conclusiones de carácter cronológico. En general, únicamente podemos afirmar que nuestras piezas deben datarse en los cuatro siglos anteriores a la Era, con mayor probabilidad en los dos últimos para los bordes, como se ha señalado arriba.

${ }^{13}$ Este mismo fenómeno se repite especialmente en otros tipos anfóricos del yacimiento: Dr. 2-4 valencianas, Beltrán II B y Gaul. 4, con pastas de apariencia bastante similar muy depuradas (ver fig. 4).

${ }^{14}$ Sobre pastas anfóricas de origen valenciano véase: ARANEGUI, 1981; ARANEGUI y MANTILLA, 1987, ABAD y SALA, 1993, 206-207.

${ }^{15}$ La ausencia de labio, que caracteriza a nuestras piezas, tampoco parece tener una significación cronológica en las ánforas ibéricas catalanas (MIRÓ, 1984, 180).

${ }^{16}$ Un tipo similar al I-5 abunda en niveles del s. II a.C. en Itálica (LUZÓN, 1973, 47, lám. L, fịg. 14A).

${ }^{17}$ Para 6,1 podemos destacar un borde del Tossal de Manises (RIBERA, 1982, fig. 23, 5) y otro de La Serreta d'Alcoi (ibid., fig. 14, 5) - ambos forman parte de ánforas completas del tipo I-5 de Ribera-; 6,2 es semejante a un borde del último yacimiento mencionado (en un ánfora del tipo I-4 var., de RIBERA, 1982, fig. 14, 3) y a otro del nivel 3 del Cerro Macareno (PELLICER, 1978, tipo D, fig. 7 , n. ${ }^{\circ}$ 2366), fechado en el segundo cuarto del s. II a.C.; para 6,3 se conoce un ejemplar muy próximo procedente del alfar de El Campello (RIBERA, 1982, fig. 20, 6), fechado en el s. III a.C. (SIMÓN, 1990, 50), y otro del nivel 2 del Cerro Macareno (PELLICER, 1978, fig. $\left.7, n^{\circ} 209\right)$, de la segunda mitad del s. II a.C. 
Respecto a su función, Ribera (1982, 122-123) opina que servirían para guardar y conservar alimentos más que para transportarlos. La excepción la constituirían algunos ejemplares del tipo I-3 de procedencia subacuática, a los que hay que sumar los nuestros, si bien no podemos distinguir si su adscripción tipológica coincide con este tipo o con el I-S. Por otra parte, el contenido de estos envases no está claro: Ribera (1982) lo considera variado, mientras Miró (1984) opina que los ejemplares layetanos pudieron exportar fundamentalmente cereales durante los siglos IV y III a.C.

La presencia de ánforas ibéricas en yacimientos submarinos se documenta desde, al menos, el s. III a.C. hasta incluso mediados del I d.C. ${ }^{18}$. en el caso de los pecios tanto como cargamento principal como para uso de la tripulación. Nuestras piezas suponen un eslabón más en esta cadena de hallazgos subacuáticos, todavía escasamente atestiguados en el País Valenciano (vid. FERNÁNDEZ IZQUIERDO, 1984, 198).

Mañá C2. En primer lugar, contamos con un cuello identificable con el tipo C2a de J. Ramón (1981, 10-11, fig. 6, 1 y 2 ), tanto por sus características formales como por la pasta. Se trata de una variante esencialmente centro-norteafricana, el producto cartaginés más característico desde la II Guerra Púnica hasta la caída de Cartago en 146 a.C. (LANCEL, 1977; CHELBI, 1980; VAN DER WERFF, 1978, subtipo 1). Aunque su comercialización abarca todo el s. II a.C., el momento de su máximo apogeo es el segundo cuarto del mismo (RAMÓN, 1981; GUERRERO y ROLDAN, 1992). En el País Valenciano hay documentados varios ejemplares de Mañá C2, redefinidos por Guerrero y Roldán $(1992,48)$ como Mañá C2a. Se han publicado ejemplares de Burriana (Castellón) (FERNÁNDEZ IZQUIERDO, 1990, fig. 13, 1), Sagunto (MANTILLA, 1986, fig. 3, 1), dos procedentes de colecciones privadas de Denia (Alicante) (GISBERT, 1985, fig. 16, 1 y 2) y otro del Tossal de la Cala (Benidorm-Finestrat, Alicante) (RIBERA, 1982, fig. 16, 2).

La segunda pieza, prácticamente completa, corresponde al tipo C2b de Ramón (1981). Se produjo en talleres situados a ambos lados del Estrecho de Gibraltar, y se comercializó a partir del último cuarto del s. II y sobre todo durante la primera mitad del s. I a.C. (GUERRERO y ROLDAN, 1992; PONSICH, 1968, 12, fig. 2, IV; BOUBE, 1975, 231). En el País Valenciano se atestigua en Torre la Sal (Cabanes, Castellón) -dos ejemplares-(FERNÁNDEZ IZQUIERDO, 1982, fig. 5, 3), Burriana (FERNÁNDEZ IZQUIERDO, 1980 , fig. 13, 2), Sagunto (MANTILLA, 1986, fig. 3, 2) y Tossal de la Cala (RIBERA, 1982, 62-63, figs. 17, 3 y 17, 5).

Sobre la problemática de su contenido principal, las evidencias en favor de las salazones de pescado parecen dema-

${ }^{18}$ Puede consultarse un completo elenco en MIRÓ, 1984, 165-180 y en RIBERA, 1982, 105.

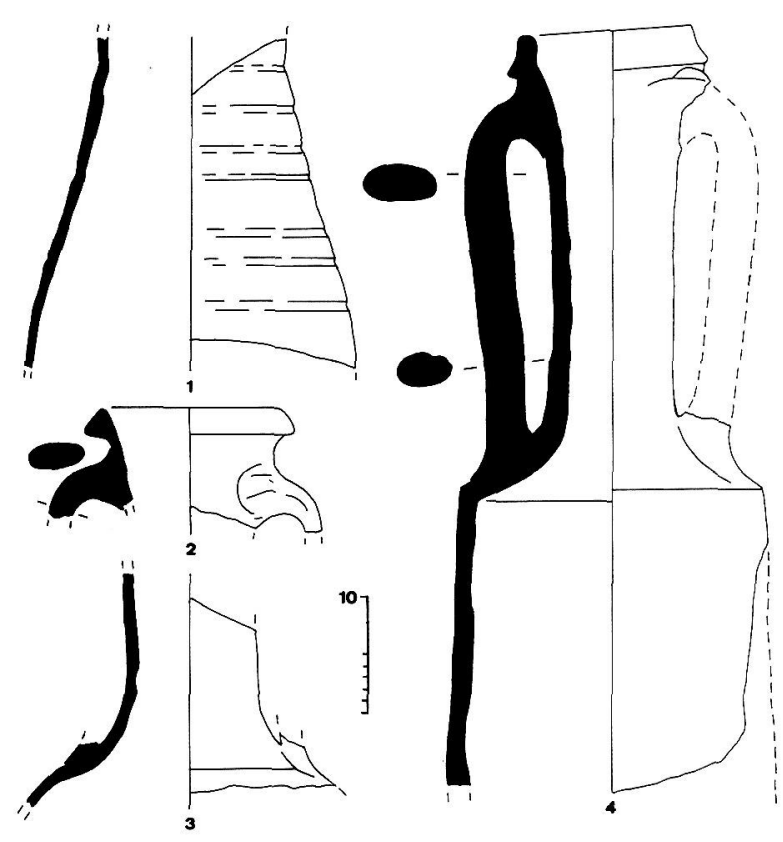

Fig. 7.-

siado aisladas, como bien argumenta J. Ramón (1981, 16$17)^{19}$. Por otra parte, en el País Valenciano conocemos todavía, según A. Ribera $(1982,109)$ un número relativamente escaso de Mañá C2, que deben ponerse en relación con el flujo comercial procedente del norte de África y zona hispana del Estrecho, durante la época republicana, a lo largo de las costas europeas del Mediterráneo occidental.

Púnico-ebusitana (PE-13 a PE-18). El fragmento 7,1 no permite una aproximación cronológica - podría corresponder a tipos datables entre mediados del s. V a.C. y el tercer cuarto del s. I d.C- - pero sí al menos determinar su origen ebusitano, conforme con el tipo de pasta.

Grecoitálicas: lo que conservamos de las piezas 7,2 y 7,3 no permite aplicar la fórmula propuesta por A. Tchernia (1936, 309) para diferenciarlas de las Dr. 1 A. Hasnard y Lemoine (1981, nota 33) utilizan el labio para diferenciar los fragmentos en sus prospecciones, con resultados positivos contrasta$\operatorname{dos}^{20}$ : en el caso de nuestro fragmento 7,2 la relación altura/grosor máximo del labio (2.3/2.6) es inferior a 1, lo que autoriza su clasificación en este grupo. Por lo que respecta a

\footnotetext{
19 Sobre el particular cf. DRESSEL, 1879, 105, n. ${ }^{\circ} 86$; CIL XV, 4730, ZEVI, 1966, 220-221; DOMERGUE, 1973, 110; PONSICH y TARRADELL, 1965; RIBERA, 1982, 111 y SANTAMARÍA, 1961, 172, fig. 8.

${ }^{20}$ Sobre este problema y las limitaciones del método véase SANMARTí, 1985, 133.
} 


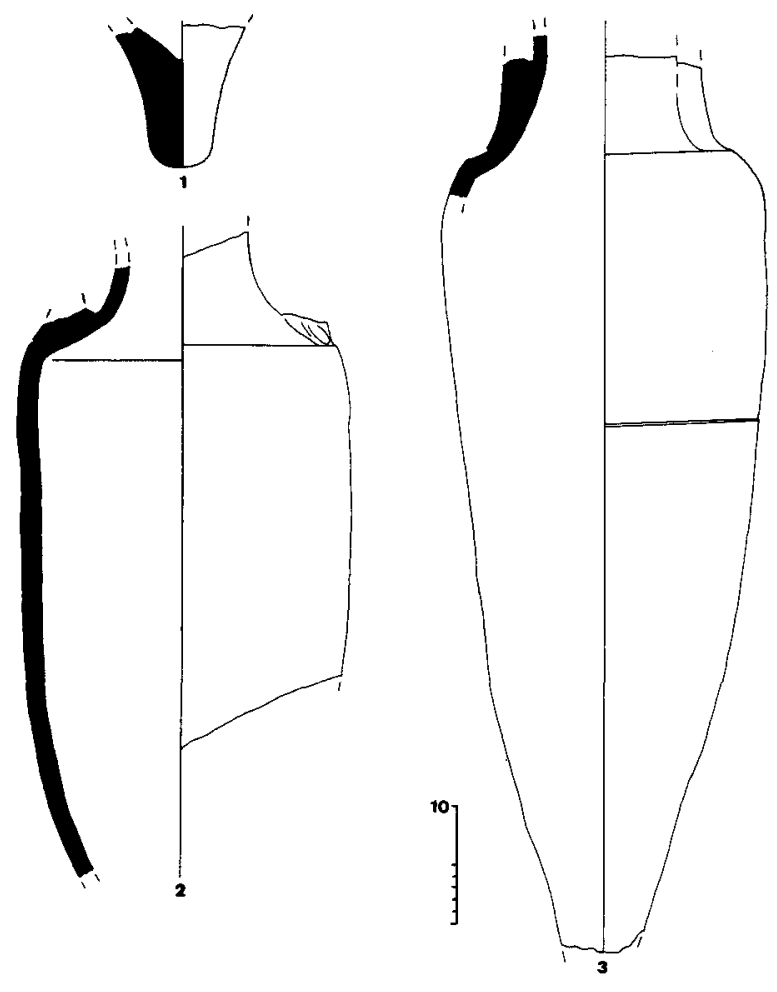

Fig. 8.-

7,2 , es principalmente la abertura del perfil del cuerpo, insinuada en el arranque de las paredes, la que nos ha dado la clave.

No cabe identificar nuestros ejemplares con la variante «antigua» de estas ánforas vinarias, escasísimamente atestiguada en las costas mediterráneas hispanas. Al menos 7,2 puede ponerse en relación con la variante «d» de E.L. Will (1982, 348-353), que esta autora sitúa en la primera mitad del s. II a.C., aunque en general hemos de datar nuestros fragmentos entre finales del s. III o comienzos del II y ca. 135 a.C. (TCHERNIA, 1986, 42; SANMARTÍ, 1985). Nos abstendremos, por otra parte, de indicar un origen geográfico concreto mientras no contemos con los análisis de las pastas. Únicamente recordaremos que debe buscarse dentro de una amplia área que cubre Italia central y meridional (WILL, 1982, 35 y 356; HERNARD et al., 1989).

Estas ánforas grecoitálicas del s. II se encuentran bien representadas en el País Valenciano: en las costas de Castellón predominan los ejemplares similares al nuestro, junto con otros que suponen la transición hacia la Dr. 1 A (FERNÁNDEZ IZQUIERDO, 1982); son igualmente numerosos en el litoral de la provincia de Valencia, donde también se ha localizado la variante antigua (s. III) en la playa de la
Malvarrosa (FERNÁNDEZ IZQUIERDO, 1984, 98); en la provincia de Alicante destaca el importante lote del Tossal de Manises (BELTRÁN, 1970, 344, figs. 120, 121 y 123, 1-5), y abunda en general en los poblados ibéricos de la zona, como en La Escuera (NORDSTROM, 1967; ABAD, 1986), aunque, conocemos todavía pocos hallazgos subacuáticos ${ }^{21}$.

Dressel 1. Para la diferenciación de los distintos tipos de este ánfora vinaria (A, B y C) actualmente no resultan suficientes las tipologías de Lamboglia (1955) y Benoit (1957) (HERNARD y LEMOINE, 1981, 251; TCHERNIA, 1986, 312-320), y se vienen utilizando nuevas pautas, a la espera de una revisión tipológica en profundidad. Por lo que respecta a la pieza 7,4, su identificación con el tipo Dr. 1 A es conforme a los criterios expuestos por Stockli $(1979,126$, a cuyo trabajo remitimos), y sus dimensiones son similares a las de los ejemplares del campamento numantino de Peña Redonda (SANMARTí, 1985). En cuanto a la pasta, se asemeja a la de la clase B de este último yacimiento, que Sanmartí cataloga como centroitálicas, pero habrá que esperar a los análisis para conocer con exactitud su origen. En cualquier caso, no se corresponde con las conocidas pastas "volcánicas", como sí parece suceder con las piezas 8,1 y 8,2. La primera de éstas debe catalogarse dentro de las Dr. 1 A si utilizamos el criterio de Stöckli (altura interior del pivote $<12.5 \mathrm{~cm}$.), mientras no está clara la adscripción de 8,2 a las Dr. 1 A o B, si bien la carena del hombro, poco marcada, es más característica del primer tipo. En cuanto a las cronologías, recordemos que la forma Dr. 1 A se genera entre 145-135 (TCHERNIA, 1983 y 1986, 42) y supera la mitad del s. I a.C., llegando quizá a los momentos finales de la producción de Dr. 1, hacia 10 a.C. (PEACOCK y WILLIAMS, 1986, 87; TCHERNIA, 1986, 320; FURGER-GUNTI, 1979, 98), mientras la Dr. 1 B parte de comienzos del s. I a.C. y alcanza aquella misma fecha final (cf. TCHERNIA, 1986, 126 y 320 ). Por su parte, la pieza 8,3 es, sin duda, una Dr. 1 C., datable a partir de finales del s. II hasta finales del I a.C. o incluso comienzos del I d.C. (BELTRÁN, 1970, 329; WILL, 1979; TCHERNIA, 1986, 126; COMAS, 1985 y 1987). Esta variante $\mathrm{C}$ se fabrica principalmente en Campania y, probablemente, también en Etruria (cf. PEACOCK y WILLIAMS, 1986, 91-92), pero no estamos en condiciones de concretar todavía la procedencia de nuestro ejemplar.

En el País Valenciano los tipos Dr. 1 son muy abundantes en yacimientos de tierra, y comunes en contextos subacuáticos republicanos, aunque porcentualmente parece menos frecuente la Dr. 1 B (MARTIN y SALUDES 1966; WAGNER, 1978; FERNÁNDEZ IZQUIERDO, 1982; idem, 1984, 98-99; RIBERA y FERNÁNDEZ, 1985; SALA, 1989; BERTO, 1991.

Lamboglia 2. Ambas piezas $(9,1$ y 9,2) presentan un color de la pasta muy similar, y al menos la de la primera podría

\footnotetext{
21 Sala (1989) publica dos ejemplares de la costa de Altea.
} 

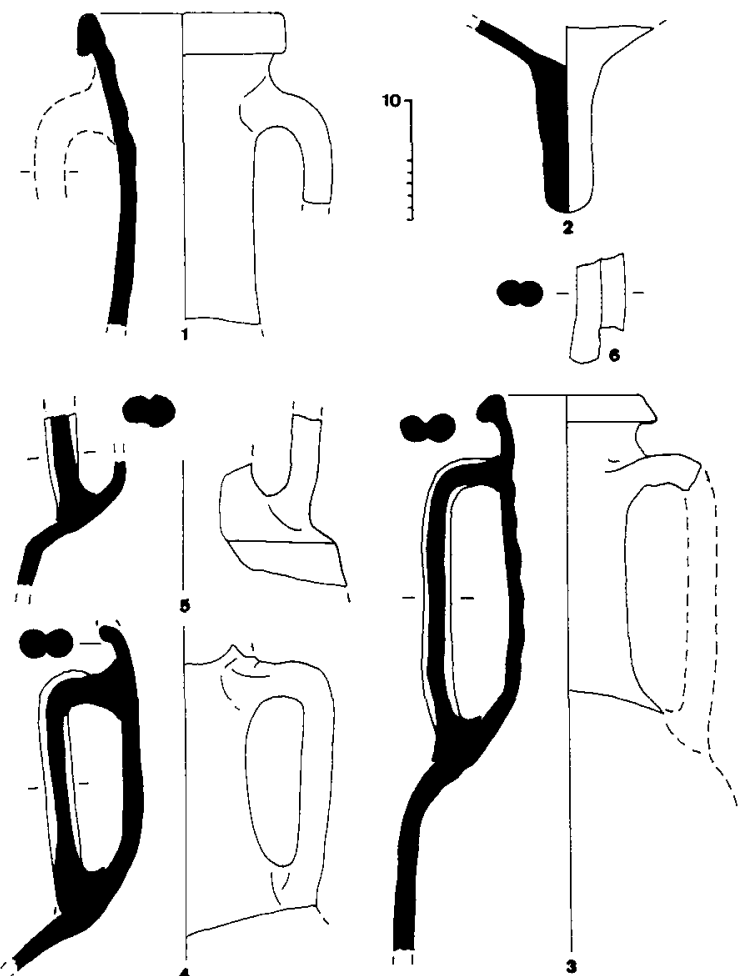

Fig. 9.-

relacionarse con las características del taller de Locavaz (Venecia oriental) (cf. CIPRIANO y CARRE, 1989, 80 ss.). Tradicionalmente se ha propuesto un origen apulio y calabrio (BALDACCI, 1968; PANELLA, 1970; BUCHI, 1971), pero no se ha atestiguado todavía, con seguridad, alfar alguno que fabricara Lamb. 2 en la zona. En cambio, sí se conoce varios talleres que las fabricaron más al norte, en el Piceno y la Venecia oriental. Cronológicamente hay que situarlas a partir del último cuarto del s. II y durante el I a.C. (CIPRIANO y CARRE, 1989, 82-85), aunque su aparición en las costas de la Península Ibérica se da sobre todo en este último (cf. BELTRÁN, 1970, 353; NOLLA-NIETO, 1989, 382; COMAS, 1985, 90). Sobre su contenido principal se ha producido una larga controversia. Frente a quienes han querido ver una exportación de aceite (PANELLA, 1970; BUCHI, 1971) se está imponiendo la idea de que transportaron vino (FORMENTI, HESNARD y TCHERNIA, 1978; BELTRÁN, 1980, 203; TCHERNIA, 1980, 305-307; id. 1986, 53 ss.; CIPRIANO y CARRÉ, 1989, 80-85), mientras el aceite medio-adriático pudo transportarse en las ánforas «ovoidales adriáticas» (CIPRIANO y CARRÉ, 1989, 77-80).

Las ánforas Lamb. 2 se distribuyen especialmente por las costas adriáticas, el valle del Po y el Mediterráneo oriental. Su presencia en numerosos pecios del Mediterráneo occidental

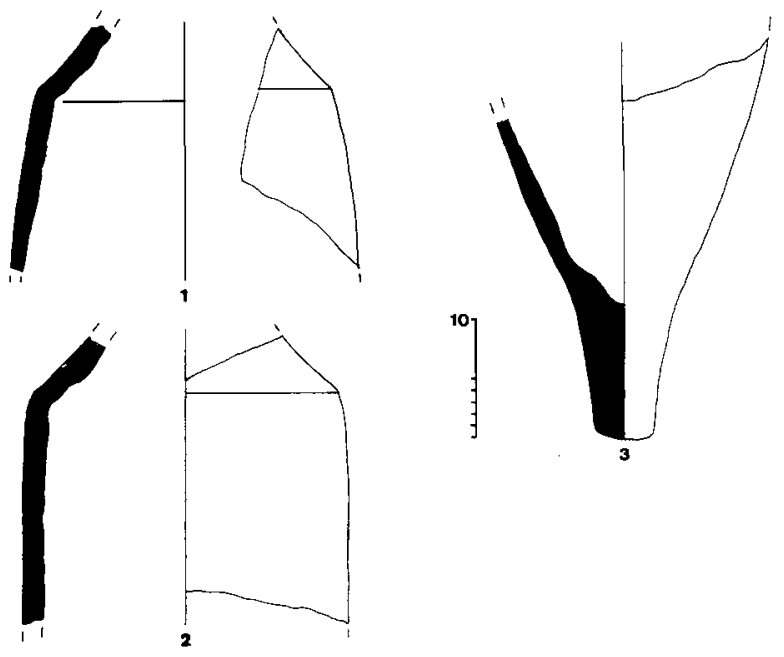

Fig. 10.-

no debe ser sobrevalorada, según M.B. Carré (CIPRIANO y CARRÉ, 1989, 85): en la mayor parte de los casos - si exceptuamos los pecios de Sa Nau Perduda, Punta de Algas y la Colonia de Sant Jordi- no se hallan más que unas cuantas piezas para uso de la tripulación o como complemento del cargamento. Ello explica su escasez en contextos de tierra tanto en Francia como, en menor medida, en España. No es, por tanto, un tipo abundante en las costas del País Valenciano, donde únicamente conocemos algunos hallazgos aislados (MARTIN y SALUDES, 1966, 164, fig. 10, 3, lám. III c y 166, fïg. 12; BELTRÁN, 1970, 352-353; RIBERA y RIPOLLÉS, 1977, 159-160; FERNÁNDEZ IZQUIERDO, 1980, 157, fig. 4, 6.-168, figs. 8, 3 y 8, 6-178, fig. 10, 2-3-187, fig. 13,6; id. 1984, 98; ARANEGUI, 1982, 87-88, fig. 36, 7, lám. XXI, 2; BLANQUEZ, 1982, 48, fig. 5-7; RIBERA y FERNÁNDEZ, 1985; SALA, 1989; BERTO, 1991).

Dressel 2-4. Tan sólo tres fragmentos pueden estudiarse desde el punto de vista formal: tanto 9,4 como 9,3 y 10,3 se pueden adscribir a las variantes tarraconenses (cf. TCHERNIA, 1971; FARIÑAS, FERNÁNDEZ y HESNARD, 1977). Ahora bien, dentro de la «familia» tarraconense existen dos grupos bien definidos y distinguibles principalmente por la pasta: las ánforas layetanas suelen contener un desgrasante de origen granítico (cuarzo, feldespato y mica) (TCHERNIA y ZEVI, 1972; PASCUAL, 1977), mientras las valencianas son muy depuradas, de fractura recta y colores rosados, beiges u ocres, con escasos desgrasantes micáceos finos y silíceos, a veces inapreciables (ARANEGUI y MANTILLA, 1987, 100104; ARANEGUI, 1981; GISBERT, 1987). De acuerdo con estas características, 9,$5 ; 10,1 ; 10,2$ y 10,3 son probablemente de origen catalán, mientras 9,3; 9,4 y 9,6 tienen pastas valencianas. Por el contrario, todavía no han aparecido piezas pro- 


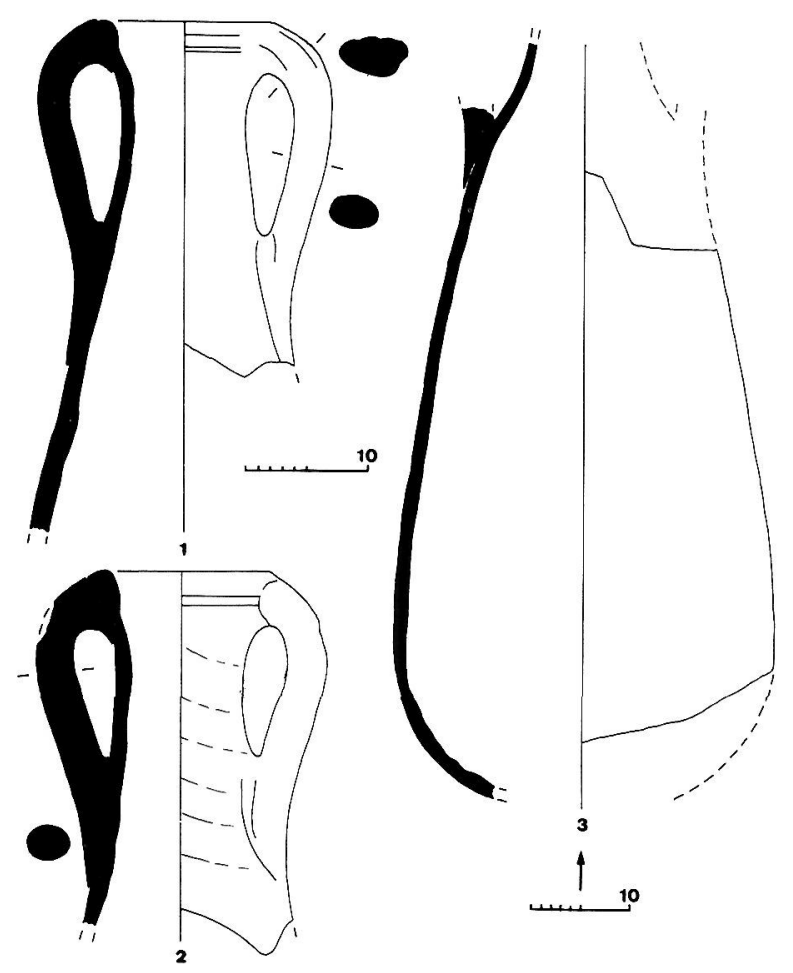

Fig. 11.-

cedentes de otras zonas productoras, entre las que destacan el Lacio, Campania y Etruria (cf. HERNARD, 1977; PEACOCK, 1977; PANELLA, 1981). En el País Valenciano parece común esta abundancia relativa de Dr. 2-4 tarraconenses, como sucede en Valentia (FERNÁNDEZ IZQUIERDO, 1982, 100) o en el Portus Illicitanus (SANCHEZ y LLOBREGAD, 1984, 138-139). En la primera de ellas parece observarse una presencia importante de ejemplares valencianos. Por el contrario, en la costa mediterránea hispana son muy escasos los hallazgos de Dr. 2-4 itálicas (COMAS, 1987; NOLLA y NIETO, 1989, 382). Cronológicamente debemos ubicar nuestras piezas entre Augusto-Tiberio (COMAS, 1985 y 1987) y comienzos a mediados del s. II d.C. (ZEVI, 1966).

Beltrán II B. Un total de veintiuna piezas y un número mínimo de ejemplares de quince convierten a este tipo en el más numeroso de los atestiguados en el fondeadero. Sus pastas presentan una absoluta homogeneidad: muy depuradas, duras, en ocasiones con escasos desgrasantes de aspecto micáceo y finos. Se aprecia una alteración generalizada y característica del color, por la acción química del medio marino, que penetra alrededor de un centímetro en su interior, dando tonos pardo-grisáceos y grises medios a oscuros. Únicamente en el labio, por lo común engrosado, se conserva el color castaño original, que ha podido registrarse en las piezas 11,1 y 11,2. Los rasgos formales del cuello son, igualmente, homogéneos:
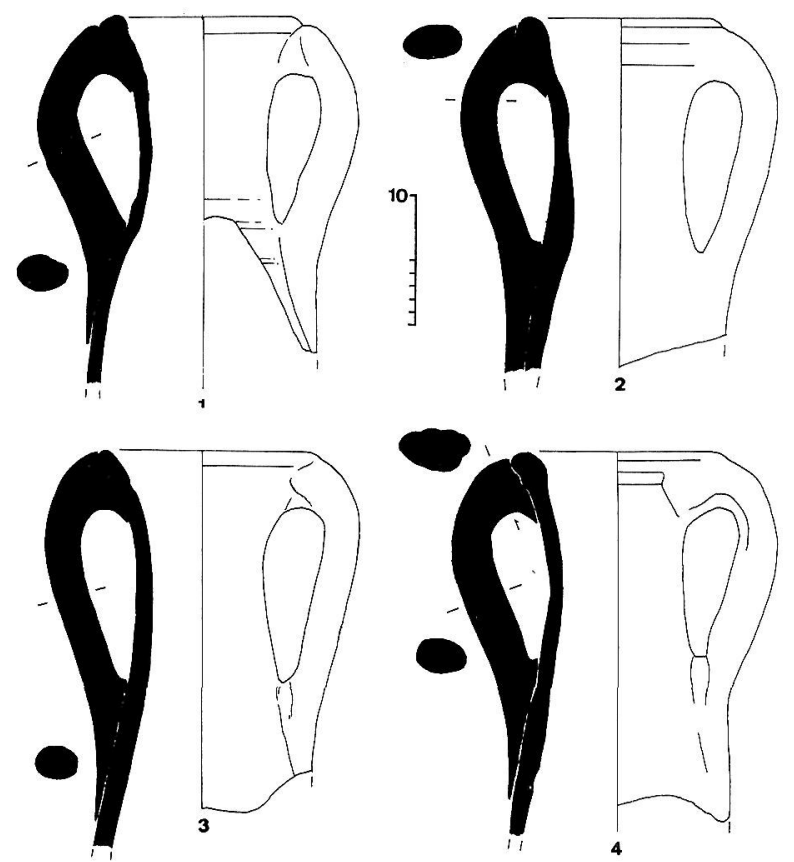

Fig .12.-

la unión con el cuerpo se realiza sin solución de continuidad, boca exvasada con labio engrosado de sección triangular; en ocasiones una a tres molduras bajo el exterior del borde; asas unidas a este último, con sección ovalada, más ancha cerca de aquél, donde presentan invariablemente tres estrías longitudinales, que se pierden en sus dos tercios inferiores (con frecuencia la estría de la derecha apenas insinúa su comienzo, mientras las otras dos son más largas); los diámetros exteriores del borde oscilan entre 14.4 y $18.6 \mathrm{~cm}$., con una media de 16.9 y una mayor frecuencia entre 15.2 y 16.4 (6 casos) y 17.2 y 18.6 ( 8 casos); para dar solidez a la unión interior de la base del asa con el cuerpo se adhiere generalmente una pequeña tira de arcilla (ver p. ej. figs. 11,2; 12,3, y 12,4); el único cuerpo conservado es marcadamente piriforme, con un diámetro máximo de $38.5 \mathrm{~cm}$. A pesar de carecer de piezas completas, los elementos con los que contamos permiten estimar en torno a $125 \mathrm{~cm}$. La altura total del tipo, ciertamente considerable. No se ha documentado información epigráfica alguna, generalmente escasa en las Beltrán II B, si bien la acusada erosión superficial de gran parte de los ejemplares puede haberla eliminado.

El elevado porcentaje de este tipo plantea un problema de interpretación. Evidentemente, se trata de piezas fabricadas en la misma zona (e incluso en el mismo centro), ya que los detalles formales y la pasta coinciden plenamente. La única región donde está comprobada la fabricación de esta variante del tipo II $\mathrm{B}$ es el Algarve (posiblemente en la comarca de Loulé) 

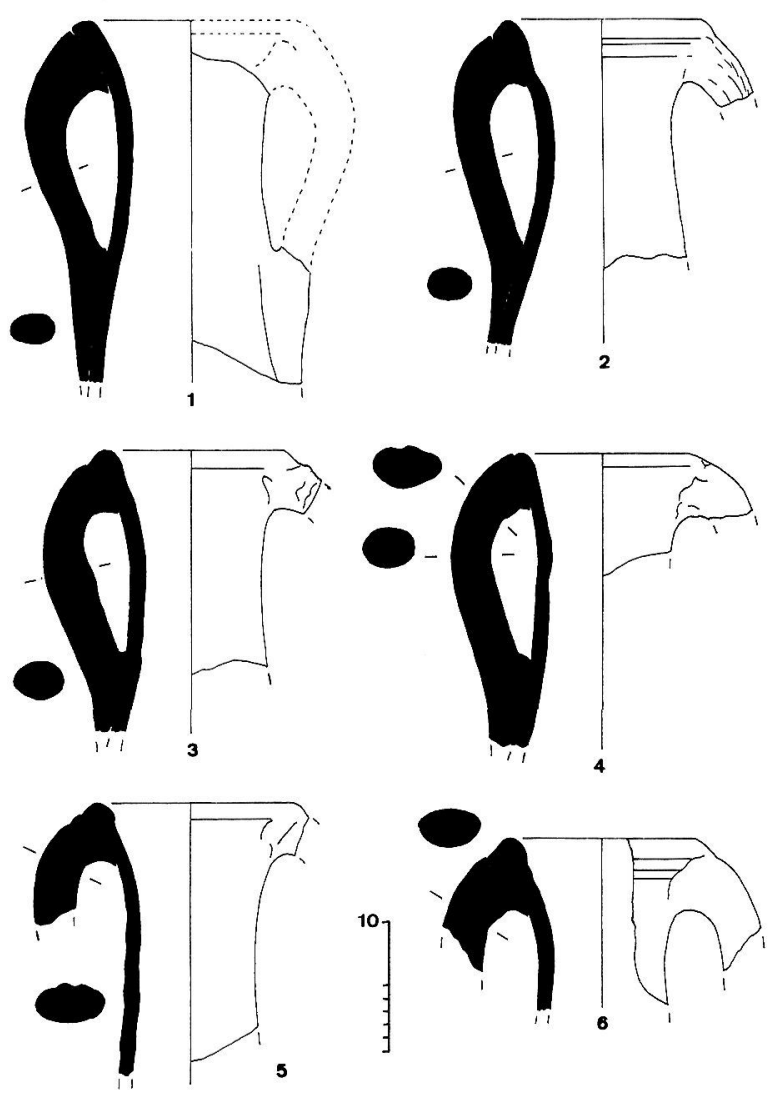

Fig .13.-

(PARKER, 1977; DIAS, 1987, 184, fig. 7,11; ALARCAO y MAYET, 1990, 65), donde A.M. Dias la clasifica como «Lusitana 11». Todas las características formales generales (incluso la relación altura total/ diámetro máx. del cuerpo= 3.3) relacionan a nuestros ejemplares con los portugueses, mientras la pasta de los mismos (muy fina y blanda, de colores beige-amarillentos y rosados, con pequeños cuarzos, calcitas y minúsculas micas, muy distintas de las de las producciones lusitanas más características) se asemeja a la de nuestros ejemplares. Ahora bien, aun tomando este origen como el más probable, hay varios aspectos que llaman poderosamente la atención: la hiperabundancia de este tipo, originario de un mismo centro productor, en la Platja de la Vila, frente a la rareza de otros envases de salazón; el contraste que supone este elevado porcentaje con la existencia de industrias de derivados de pescado en las costas de la provincia de Alicante (PONSICH y TARRADELL, 1965; MARTIN, 1970; MARTIN y SERRES, 1970; ARANEGUI, 1981; SANCHEZ, 1986 y 1991; SANCHEZ, BLASCO y GUARDIOLA, 1986); la similitud de las pastas de nuestras piezas con las propias del País Valenciano (supra, Dr. 2-4). No podemos descartar, pues,

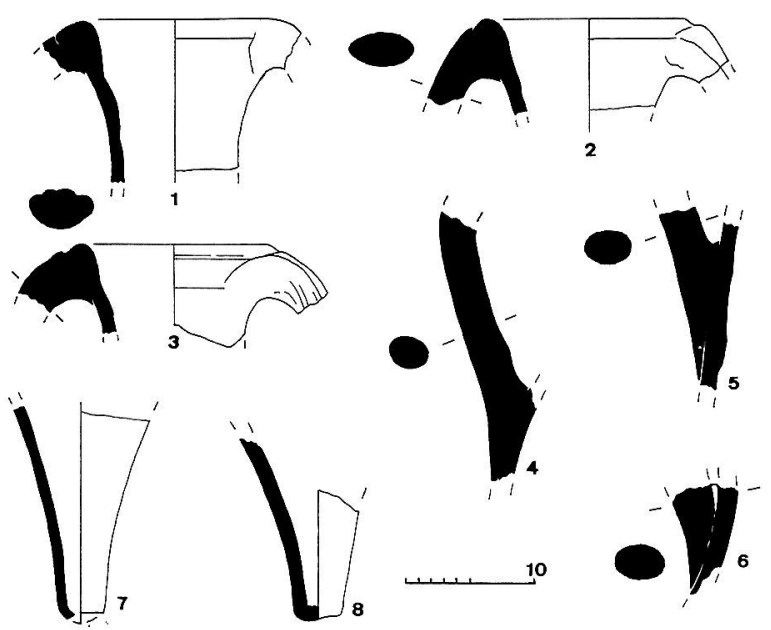

Fig .14.-

una fabricación local (quizá imitación, como ocurre con otras formas en la región) de estas ánforas, al menos mientras no dispongamos de los análisis comparativos de laboratorio ${ }^{22}$. Recordemos, a este respecto, que los envases en los que se exportó las salazones de la franja costera alicantina son, por el momento, desconocidos (a excepción de las Dr. 7-11 de Punta de l'Arenal, (Xabia): MARTIN, 1970, 139 ss.; BELTRÁN, 1977, 101). La distribución de los hallazgos en el fondeadero ayuda bien poco a la interpretación: en nuestras prospecciones hemos localizado directamente tan sólo cuatro de las veintiuna piezas. El resto fueron extraídas por el club CEASUB, y desconocemos, por tanto, su localización y circunstancias exactas, si aparecieron dispersas o concentradas (y por tanto si cabría o no pensar en un pecio dentro del fondeadero o en sus proximidades), etc. Los cuatro fragmentos mencionados se hallaron muy próximos entre sí, en una prospección circular, sobresaliendo del talud del frente de erosión de la pradera de Posidonia, en un mismo nivel, y junto a tres cuellos de la forma Gaul. 4 (fïg. 3), pero no se encontró evidencia alguna de la pertenencia de estos materiales a un pecio, y en principio hay que relacionarlos con el fondeadero.

Cronológicamente, el tipo Beltrán II B se ubica entre los comienzos del s. I d.C. y mediados del siguiente (PANELLA, 1973; DIAS, 1987) o incluso comienzos del s. III (FABIAO y CARVALHO, 1990, 56). En el País Valenciano es relativa-

\footnotetext{
${ }^{22}$ Próximamente se publicará los resultados de los análisis en proceso de realización, así como algunas piezas nuevas. Por otra parte, hemos de anotar que no existen evidencias de la existencia de una industria local de salazón en La Vila Joiosa, si bien es cierto que nuestro conocimiento de sus yacimientos romanos es todavía extremadamente superficial.
} 


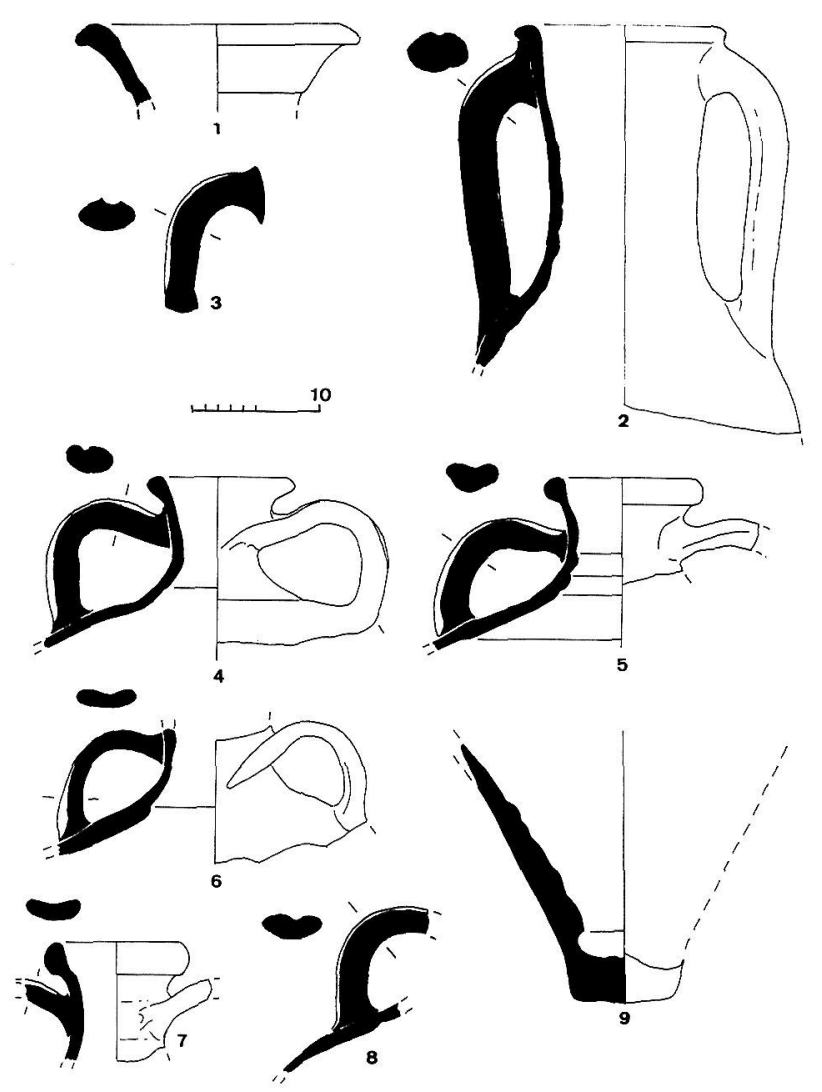

Fig .15.-

mente abundante (FERNÁNDEZ IZQUIERDO, 1982 y 1984), aunque falta un estudio tipológico pormenorizado.

Dressel 7-11. Un único ejemplar, cuyos mejores paralelos se datan entre Augusto y Nerón (BELTRÁN, 1970, nota 846; ULBERT, 1959, 80-81, lám. 11), aunque en general la forma puede alcanzar los comienzos del s. II d.C. La pasta es de aspecto bético, origen que corresponde a la mayor parte de las piezas halladas en aguas del País Valenciano, por las que discurría la ruta hacia distintas provincias del Imperio (FERNÁNDEZ IZQUIERDO, 1982, 121 y 1984, 100; SÁNCHEZ y LLOBREGAD, 1984, 140; RIBERA y FERNÁNDEZ, 1985; BERTO, 1991).

Dressel 14. Una sola pieza ${ }^{23}$, ubicable cronológicamente entre los comienzos del s. I y el s. III d.C. (BELTRÁN, 1970).

\footnotetext{
${ }^{23}$ Se corresponde con la variante Beltrán IV A. Sobre la conveniencia o no de la distinción de los subtipos A y B de la Dr. 14= Beltrán IV, y los problemas de nomenclatura: PARKER, 1977; MAYET, 1990, 28 y 1990, 29-31; FABIAO y CARVALHO, 1990, 48, ALARCAO y MAYET, 1990, 65 y 248.
}

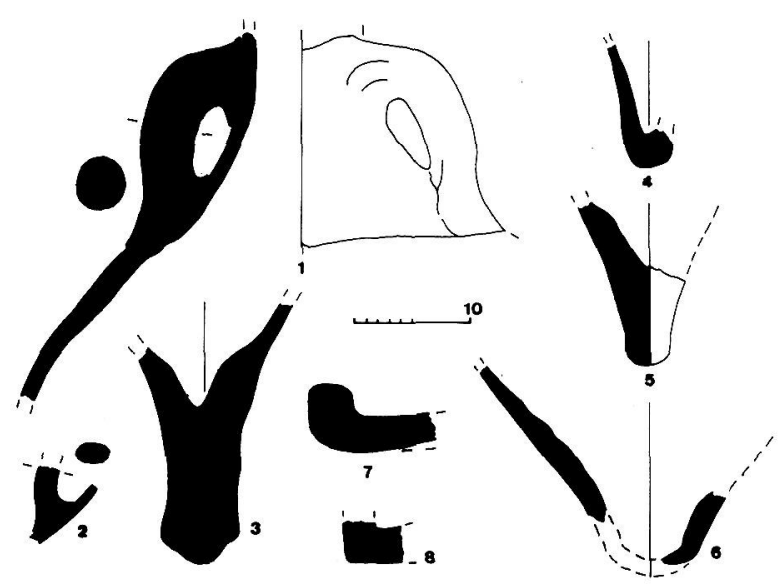

Fig .16.-

Originaria probablemente de la costa bética (BELTRÁN, 1970 y 1977, 102). Apenas encontramos referencias de esta ánfora de salazón en los trabajos publicados hasta la fecha sobre el País Valenciano (un ejemplo en BELTRÁN, 1970, 462, que cita su aparición en la Bahía de Alicante).

Haltern 70. Representada por un solo fragmento. Originaria de la Bética, puede datarse entre mediados del s. I a.C. y mediados del siguiente, y su contenido principal se ha identificado con el defrutum (COLLS et al., 1977; TCHERNIA, 1980; PARKER y PRICE, 1981). Para el País Valenciano apenas hay menciones respecto a esta forma, que tampoco es frecuente en el resto de la fachada oriental de la Península: un ejemplar de la costa de Altea (SALA, 1989, n. ${ }^{\circ}$ 2) y el Grau Vell de Sagunto (BERTO, 1991). Hay que tener en cuenta, sin embargo, que a menudo se ha confundido con otros tipos.

Gauloise 4. Con seis fragmentos y un número mínimo de cinco ejemplares, la presencia de este tipo vinario en la Platja de la Vila plantea principalmente el problema de su origen, dado que a los centros sudgálicos (WIDEMANN et al., 1978; WIDEMANN, LAUBENHEIMER y LEBLANC, 1979; LAUBENHEIMER, 1985, 1989 y 1990) hay que añadir las producciones del Ager Dianensis (GISBERT, 1986 y 1987; ABASCAL y GISBERT, 1991), con pastas en gran parte prácticamente imposibles de distinguir entre sí a simple vista ${ }^{24}$. La cronología general del tipo se sitúa entre mediados del s. I y el s. III d.C., mientras en la zona dianense se fabrica entre la época Flavia y los Antoninos. En el País Valenciano se trata,

\footnotetext{
${ }^{24}$ Agradecemos a F. Laubenheimer y a J. Gisbert sus apreciaciones a este respecto sobre el material de la Platja de la Vila. Sobre las pastas galas remitimos a la bibliografía citada. Por lo que respecta a las valencianas, ya hemos reseñado más arriba sus características.
} 


\begin{tabular}{|c|c|c|c|c|c|c|}
\hline TIPO & TOTAL & N.H.I. & \multicolumn{2}{|c|}{ xN.M.I. } & \multicolumn{2}{|c|}{ XTOTAL } \\
\hline IBERICA & 7 & 7 & 13.0 & & 11.5 & \\
\hline MANA C2a & 1 & 1 & 1.8 & & 1.6 & \\
\hline MANA CZb & 1 & 1 & 1.8 & 3.7 & 1.6 & 3.3 \\
\hline EBUSITANA & 1 & 1 & 1.8 & & 1.6 & \\
\hline GRECOITALICA & 2 & 2 & 3.7 & & 3.3 & \\
\hline DR. 1 A & 2 & 2 & 3.7 & & 3.3 & \\
\hline DR. 1 A $\quad$ o $B$ & 1 & 1 & 1.8 & 7.4 & 1.6 & 6.6 \\
\hline DR. $1 \mathrm{C}$ & 1 & 1 & 1.8 & & 1.6 & \\
\hline LAHB. 2 & 2 & 2 & 3.7 & & 3.3 & \\
\hline DR. 2-4 CAT. & 4 & 4 & 7.4 & & 6.6 & \\
\hline DR. 2-4 VAL. & 3 & 3 & 5.5 & 13.0 & 4.9 & 11.5 \\
\hline BELTRAN II B & 21 & 15 & 27.8 & & 34.4 & \\
\hline DR. $7-11$ & 1 & 1 & 1.8 & & 1.6 & \\
\hline DR. 14 & 1 & 1 & 1.8 & & 1.6 & \\
\hline HALT. 70 & 1 & 1 & 1.8 & & 1.6 & \\
\hline GAUL. 4 & 6 & 5 & 9.3 & & 9.8 & \\
\hline DR, 20 & \pm & 1 & 1.8 & & 1.6 & \\
\hline BYZACENA & 2 & 2 & 3.7 & & 3. 3 & \\
\hline INDETERM I NADO & 3 & 3 & 5.5 & & 4.9 & \\
\hline
\end{tabular}

Tabla 3.- Cuadro sinóptico de los porcentajes correspondientes a cada tipo sobre el $n^{\circ}$.total de piezas anfóricas y sobre $n^{\circ}$ mínimo de individuos (ánforas)

en general, de una forma escasamente representada en contextos de tierra (FERNÁNDEZ IZQUIERDO, 1982 y 1984) y algo más abundante en los subacuáticos: así en la playa de El Saler-Pinedo (FERNÁNDEZ IZQUIERDO, 1984), el Grau Vell (BERTO, 1991) o La Mata (en Torrevieja, donde quizá se trata de un pecio: GARCÍA MENÁRGUEZ, 1991). A. Fernández (FERNÁNDEZ IZQUIERDO, 1984, 99) opina que fueron utilizadas, a su paso por las costas valencianas, como recipientes exclusivos de transporte, ya que no se documentan, por ejemplo, en la ciudad de Valentia.

Dressel 20. La única pieza con forma es un tercio superior, al que le falta el borde. No creemos que se pueda extraer conclusiones cronológicas fiables de este fragmento a partir de los rasgos formales, dadas las dificultades de clasificación de las distintas variantes de Dr. 20, al menos desde el punto de vista de su evolución temporal ${ }^{25}$. Recordemos que puede datarse esta forma olearia bética entre Tiberio y el s. IV d.C., con una considerable reducción de su exportación a partir de mediados del s. III (cf. PEACOCK y WILLIAMS, 1986, 136). En el País Valenciano se encuentra escasamente representada, ya que existió una producción local de aceite (SÁNCHEZ y LLOBREGAD, 1984, 140-143; FERNÁNDEZ IZQUIERDO, $1984,101)$. No obstante, la ruta comercial de las Dr. 20 recorrió las costas del País Valenciano, por lo que se documentan en cierta cantidad en hallazgos subacuáticos (FERNÁNDEZ IZQUIERDO, 1982 y 1984). E. Bertó (1991) no cita su presencia en el fondeadero del Grau Vell.

Formas bajoimperiales de Africa Byzacena. No es posible hacer precisiones formales o cronológicas sobre la pieza 16,2, (en general son productos de los siglos IV a VI d.C.), mientras el pivote 16,3 puede adscribirse al tipo Keay XXV (KEAY, 1984, 191-198; MANACORDA, 1977, 121 y 180

${ }^{25}$ A este respecto, cf. NIETO et al., 1989, 63-65.

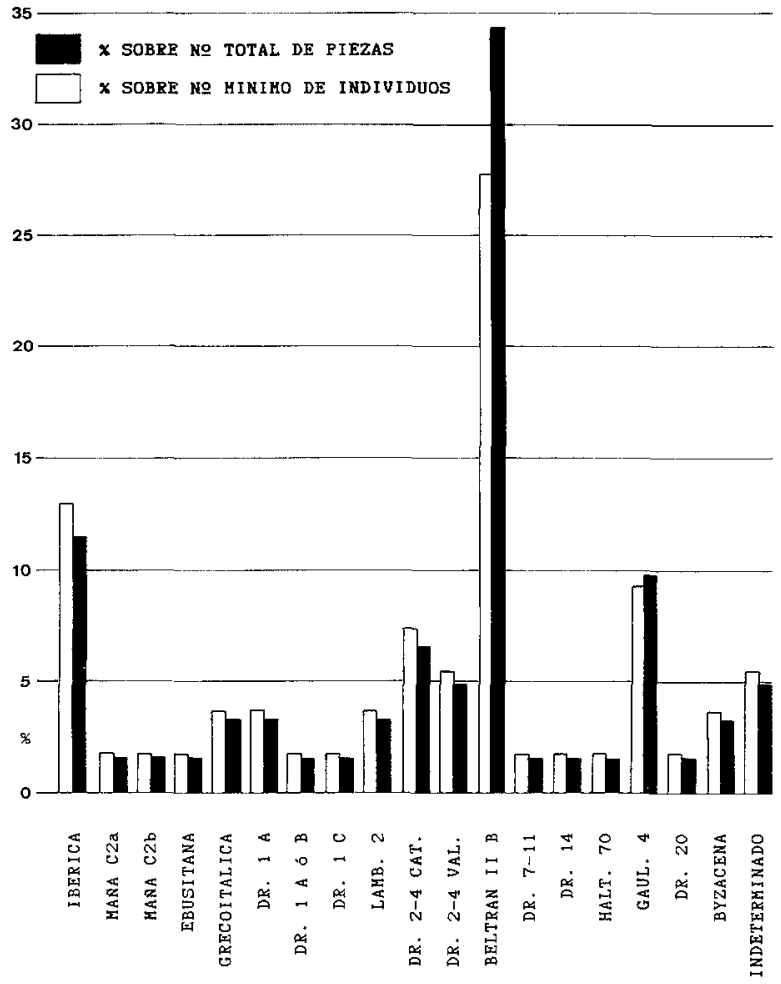

Fig. 17.- Número de piezas de cada tipo (en blanco, número mínimo de individuos).

ss.), datado por aquel autor entre finales del s. III y mediados del V. Existe una cierta discusión sobre el contenido principal de estas producciones bajoimperiales del área tunecina, pero es probable que transportaran distintos productos, y principalmente salazones y aceite.

Otros fragmentos de forma indeterminada. Tres pivotes $(16,4 ; 16,5$ y 16,6$)$ de difícil identificación formal. Unicamente cabe apuntar un claro origen layetano para el segundo de ellos, por el tipo de pasta.

\section{CONCLUSIONES}

Por lo que respecta a los márgenes cronológicos mínimos del yacimiento, estos se sitúan en el siglo II a.C. (ánforas Mañá C2a y grecoitálicas) y segunda mitad del s. V d.C., si bien podrían verse ampliados en el futuro, al menos hasta el s. IV a.C., dada la proximidad de un poblado del Ibérico Pleno, situado sobre el casco antiguo de La Vila Joiosa. En cualquier caso, los límites propuestos sintonizan con los registrados en otos fondeaderos de la costa mediterránea: así el Grau Vell (BERTO, 1991), donde se conocen materiales subacuáticos de los siglos II a.C. a IV d.C., pero la zona portuaria de tierra alcanza el s. IV a.C.; las costas de Castellón, donde el tráfico marítimo se documenta tímidamente desde finales del s. III 


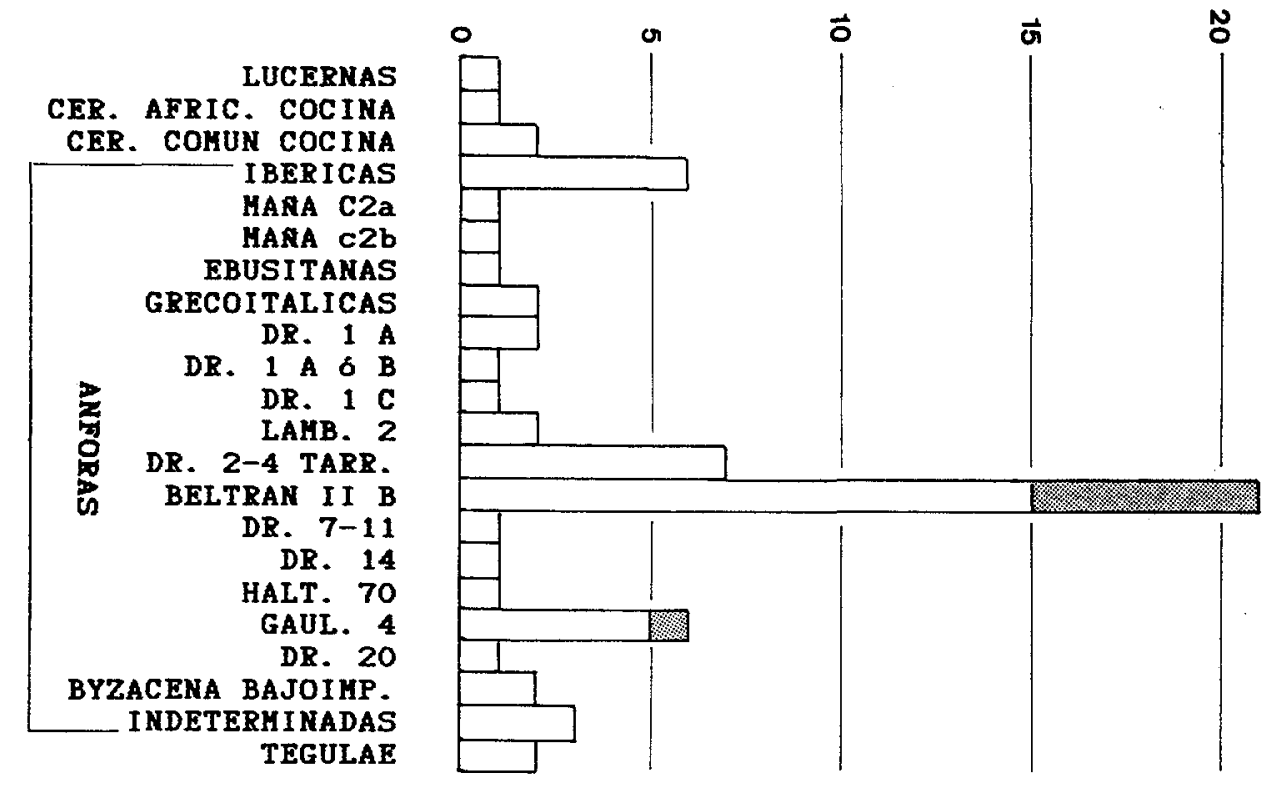

Fig. 18.- Presentación gráfica de los valores de la tabla 3.

ATLANTE VIII D 2 OSTIA III, FIG. 267 JONCH. $1974, \mathrm{~V}$ c SIH. OSTIA III, FIG. 332 I BERICA MANA C2a HAKA C2b GRECOITALICA DR. 1 A DR. $1 \mathrm{C}$

LAHB. 2

DR. 2-4 BELTRAN II B DR. 7-11 DR. 14 HALT: 70 GAUI. 4 DR. 20 KEAY XXV

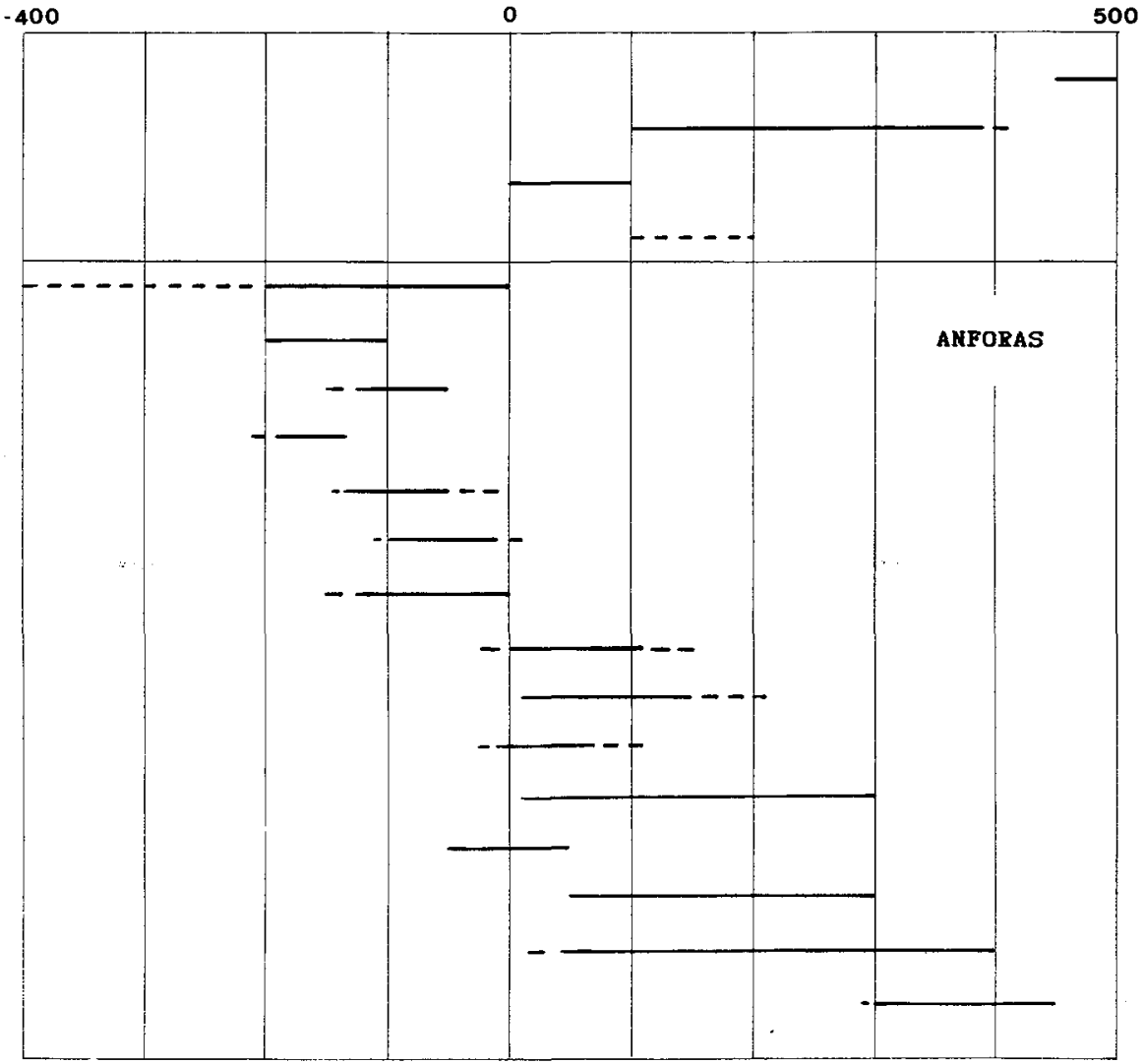

Fig. 19.- Cuadro cronológico de los tipos cerámicos documentados en la Platja de la Vila. 
a.C., y está mucho mejor representado a partir de la centuria siguiente (FERNÁNDEZ IZQUIERDO, 1982); el entorno marítimo de Valentia, donde el fondeadero de las playas de El Saler-Pinedo no aporta materiales anteriores a 138 a.C., en estrecha relación con la fecha fundacional de la ciudad (FERNÁNDEZ IZQUIERDO, 1984); o el fondeadero de la Mata (Torrevieja, Alicante), entre los siglos I a.C. y IV d.C. (GARCÍA MENÁRGUEZ, 1991). Un caso de utilización anterior al s. II a.C. lo tenemos en la playa de la Malvarrosa (FERNÁNDEZ IZQUIERDO, 1984, 97 ss.) que, sin embargo, se usa ya muy poco en el siguiente. A pesar de todo ello, opinamos que la investigación a este respecto acusa una falta de excavaciones en fondeaderos: tengamos en cuenta que, de existir capas más antiguas, éstas pueden conservarse intactas bajo el suelo marino, y por tanto quedar indocumentadas durante los trabajos de prospección. Ello puede explicar la falta de materiales prerromanos en algunos fondeaderos, como el que nos ocupa, contrastando fuertemente con la abundancia de piezas importadas en contextos terrestres $(\mathrm{ABAD}$, 1985). La gran dificultad del tránsito costero por tierra entre la Marina Baixa y las comarcas circundantes (LLOBREGAT, 1983; ESPINOSA, e.p. 3; ESPINOSA y SAEZ, e.p. 1 y e. p. 2) confiere aquí al transporte marítimo una importancia especial, y entre los puntos más indicados de este sector costero para el intercambio de productos tenemos la Platja de la Vila. De cualquier forma, es evidente la dinamización del comercio marítimo generada por la conquista romana en la costa mediterránea hispana desde el s. II a.C.

Se observa un predominio de las ánforas vinarias itálicas en los siglos II y I a.C., con ocho ejemplares, frente a siete ibéricas y otras tres de tradición púnica y variada procedencia. Este predominio de las importancias vinarias es común en los conjuntos subacuáticos de las costas mediterráneas hispanas ${ }^{26}$ y sigue una curva ascendente hasta el cambio de Era. Será entonces cuando se produzca una reestructuración del comercio marítimo, debida a los efectos de la Romanización sobre las provincias incorporadas a finales de la República: durante el Alto lmperio se evidencia en el fondeadero un predominio absoluto de envases hispanos, si bien queda por dilucidar la incógnita de la procedencia de las Gauloise 4. Respecto al tipo Dr. 20, no cabe interpretar su presencia aquí tan sólo como testimonio de la ruta comercial con destino a Italia y al Limes: en la Marina Baixa se documentan ejemplares en varios yacimientos de tierra, lo que nos habla de una cierta importación comarcal de aceite bético, quizá como consecuencia de una producción local escasa o ausente, que contrastaría con otras zonas del País Valenciano (supra). Este floruit del comercio marítimo en época altoim-

\footnotetext{
${ }^{26}$ Así en aguas del entorno de Valentia (FERNÁNDEZ IZQUIER-
} DO, 1984, 98). perial se ha documentado igualmente en las costas de Castellón (FERNÁNDEZ IZQUIERDO, 1982), y en nuestro caso está en consonancia con un período de auge económico y de la vida municipal en la Marina Baixa (ESPINOSA, e.p. 2; ESPINOSA y SAEZ, e.p. 1 y e.p. 2).

La época bajoimperial está todavía escasamente representada, tanto en variedad de tipos como en cantidad de piezas, lo que contrasta con la elevada presencia de ánforas, cerámica fina y de cocina de procedencia africana, así como de la forma anfórica Almagro 5lc, en yacimientos de tierra.

En cuanto al tipo de fondeadero, nos encontramos con un área situada frente a una playa arenosa, sin abrigo natural (excepto, muy pobre y de reducidas dimensiones, el de l'Alcocó). Los hallazgos se distribuyen, hasta la fecha, por un área de $0.2 \mathrm{~km}^{2}$, entre los 6 y los $14 \mathrm{~m}$. de profundidad, y entre los 100 y los $500 \mathrm{~m}$. de distancia de la costa (fig. 3). En esta zona fondeaban las embarcaciones, a la espera de las barcazas que realizarían las labores de transporte entre aquéllas y la costa: en este proceso debieron caer al agua gran parte de las piezas. En las costas de Castellón se ha identificado algunos fondeaderos de características similares, entre los 7 y los 10 $\mathrm{m}$. de profundidad, y a distancias entre 200 y $600 \mathrm{~m}$. de la costa (FERNÁNDEZ IZQUIERDO, 1982), y otro tanto sucede en el Grau Vell (ARANEGUI, 1976 y 1982; BERTO, 1991) y en El Saler (MARTIN-SALUDES, 1966; FERNÁNDEZ IZQUIERDO, 1982). Este proceso se vino realizando de forma muy similar por la flota de vela local de la Vila Joiosa hasta los años veinte, cuando irrumpió la navegación a motor y comenzó la construcción de un espigón en l'Alcocó. Hay que señalar que la mayoría de los puertos romanos se caracterizan por la inexistencia de una obra externa ${ }^{27}$.

A los factores, citados más arriba, que hacían de este punto un lugar conveniente para el fondeo sistemático, podemos añadir: la existencia de pozos de agua dulce cerca de la playa (fig. 4); un fondo no rocoso, adecuado para el anclaje; la escasa peligrosidad de esta parte del Mediterráneo, con pocos días de temporal al año; o la situación a medio camino entre las ciudades portuarias de Dianium y Lucentum, distantes entre sí dos jornadas de navegación.

\section{BIBLIOGRAFIA}

Las abreviaturas se corresponden con las de la revista Archäologische Bibliographie (1991), a las que se añaden:

BAR I.S.: British Archaeological Reports, Int. Series. CIAS: Congreso Internacional de Arqueología Submarina.

\footnotetext{
${ }^{27}$ Son escasos los ejemplos de malecones. En Alicante conocemos el de la playa de La Mata, de Torrevieja (Alicante) (GARCÍA MENÁRGUEZ, 1991), al que se añaden las estructuras de la Albufereta mencionadas por Figueras Pacheco (1959).
} 
EAE: Excavaciones Arqueológicas en España.

PLAV: Papeles del Laboratorio de Arqueología de Valencia.

SM: Studi Miscellanei.

TVSIP: Trabajos Varios del S.l.P.

ABAD, L., 1985: «Arqueología romana del País Valenciano: panorama y perspectivas», en I Jornadas de Arqueología de la Universidad de Alicante, Alicante, 337-382.

- 1986: «La Escuera», en VV.AA.: Arqueologíá en Alicante, 19761986, 143-147.

ABAD, L. y ABASCAL, J. A., 1991: Textos para la historia de Alicante. Edad Antigua, Alicante.

ABAD, L. y BENDALA, M., 1985: «Los sepulcros turriformes de Daimuz y Villajoyosa: dos monumentos romanos olvidados», Lucentum, IV, 147-186.

ABAD, L. y SALA, F., 1993: El poblado ibérico de El Oral (San Fulgencio, Alicante), TVSIP, 90, Valencia.

ABASCAL, J.M. y GISBERT, 1991: «Numismática y evidencia arqueológica en el alfar romano de la Almadrava (SetlaMirarrosa-Miraflor)», Lucentum, IX-X (1990-91), 133-160.

ALARCAO, A. y MAYET, F. Eds., 1990: Anforas Lusitanas. Tipología, Produçao, Comércio, Actas de las Jornadas de Conímbriga (1988), París.

ALMAGRO, M., 1953: Las necrópolis de Ampurias, 1, Barcelona.

ALMAGRO GORBEA, M. y VILAR, B., 1966: «Sello inédito de madera hallado en el pecio del Cap Negret», RStLig, XXXII, 323-336.

ARANEGUI, C., 1981: «La producción de ánforas romanas en el País Valenciano: estado de la cuestión», ArchPrehistLev, XVI, 529-338.

- 1982: «Excavaciones en el Grau Vell (Sagunto, Valencia). Campañas de 1974 y 1976», TVSIP, 72, 74-80.

ARANEGUI, C. y MANTILLA, A., 1987: «La producción de ánforas Dr. 2-4 de Sagunto», en VV.AA. 1987, 100-103.

BALDACCI, P., 1968: «Alcuni aspetti dei commerci nei territori Cisalpini», Atti del Centro di Studi e Documentazione sull'ltalia Romana, I, 1967-68, 7-50.

BELTRÁN LLORIS, M., 1970: Las ánforas romanas en España, Zaragoza.

- 1977: «Problemas de la morfología y del concepto histórico-geográfico que recubre la noción-tipo. Aportaciones a la tipología de las ánforas béticas», en V.V.AA. 1977, 97-131.

- 1980: «El comercio del aceite en el valle del Ebro a finales de la República y comienzos del Imperio romano» Producción y comercio del aceite en la Antigüedad. I Congreso Internacional, Madrid, 187-224.

BENOIT, F., 1957: «Typologie et epigraphie amphoriques, les marques de Sestius», StLig, 23, 246-285.

BERTO, E., 199l: «El yacimiento subacuático», en ARANEGUI, C. (Coord.): Saguntum y el mar, Valencia, 69-78.

BLANQUEZ, J.J., 1982: Trésors sous-marins en Espagne, DossAParis, 65.

BOUBE, J., 1975: «Marques d'amphores découvertes a Sala Volubilis et Banassa», BAMaroc, IX (1973-1975) 163-236.

BUCHI, E., 1971: Banchi di anfore romane a Verona. Note sui commerci cisalpini, en VV.AA.: Il territorio veronese in eta romana, Verona, 531-637.

CAILLEUX, A. S/F: Notice sur le code des couleurs des sols, París.

CAÑADAS, M.L.; CASTILLO, R.; ESPINOSA, A. y SAEZ, F. e.p.: «Estudio de dos anclas líticas del fondeadero de la playa de la Vila (La Vila Joiosa, Alicante) Alebus, 2, Elda, 1992.

CIL XV= DRESSEL, 1899.

CIPRIANO, M.T. y CARRÉ, M.-B., 1989: «Production et typologie des amphores sur la cote adriatique de l'Italie», en VV.AA. 1989, 67-104.

COLODRON, I; RUIZ, V.; NUÑEZ, A., 1981: Memoria y hoja geológica n. ${ }^{\circ} 847$ (Villajoyosa), Mapa Geológico de España, E. 1:50.000, Segunda Serie, Instituto Geológico y Minero de España, 1." ed., Madrid.

COLLS, D. ET AL., 1977: «L'épave Port-Vendres II et le commerce de Bétique a l'époque de Claude», Archaeonatica, 1.

COMAS, M., 1985: Baetulo: les amfores, Badalona.

- 1987: «Importació i exportació de ví a Baetulo: l'estudi de les amfores», en VV.AA. 1987, 161-174.

COMPANY, Y., 1961: «Nuevo yacimiento submarino en aguas de Ibiza», II CIAS, Barcelona, 87-90.

CHELBY, F., 1980: «Découverte d'un habitat punique sur la flanc sud-est de la colline de Byrsa», CEDAC, 3 .

DENEAUVE, J., 1974: «Un dépotoir paléochrétien sur la colline de Byrsa a Carthage», AntAfr, 8, 133 ss.

DIAS, A.M., 1987: «Quadro tipologico das anforas de fabrico lusitano», APort, s. IV, vol. 5, 179-192.

DOMERGUE, C., 1973: Bélo I. La stratigraphie, París.

DRESSEL, H., 1879: «Di un grande deposito di anfore rinvenuto nel nuovo quartiere del Castro Pretorio», $B C o m, 7,36-112$ y 143-195.

- 1899: Corpus Inscriptionum Latinarum XV, Pars 1, Berlín.

ESPINOSA, A., 1989: «La Vila Joiosa romana», Revista de Arqueologia, 100, 29-36.

- 1990: «Avance del catálogo de los fondos del Museo Histórico de Villajoyosa y de la carta arqueológica de su término municipal», en INSTITUTO DE ESTUDIOS JUAN GIL-ALBERT: Ayudas a la Investigación, 1986-87, vol. III, Alicante, 147-157.

— 1993: «Els jaciments arqueològies del casc urbà de la Vila Joiosa: una interpretació de conjunt», Moros $i$ Cristians, 30, La Vila Joiosa.

— e.p. 1: «Catálogo de los fondos de épocas ibérica y romana procedente de la mitad meridional de la comarca de la Marina Baixa depositados en el Museo Arqueológico Provincial de Alicante», en INSTITUTO DE ESTUDIOS JUAN GILALBERT: Ayudas a la Investigación, 1991, Alicante.

- e.p. 2: «Prospecció geofísica al jaciment romà de TorresSecanet», en GENERALITAT VALENCIANA: Jornades d'Arqueologia de la Comunitat Valenciana. Intervencions ordinàries, Valencia, 1994.

- e.p. 3: La investigació arqueológica a la Vila Joiosa: estat de la qüestió, La Vila Joiosa.

ESPINOSA, A. y SAEZ, F., (e. p. 1): «La carta arqueológica subacuática del litoral de la provincia de Alicante», en AA.VV: Actas del II Curso de Arqueología Subacuática de la Universidad Autónoma de Madrid, Madrid, 1992.

ESPINOSA, A. y SAEZ, F. (e. p. 2): «Una propuesta de carta arqueológica subacuática: el litoral de la Provincia de Alicante», en RAMALlo, S., ED.: Aulas del Mar. Aula de Arqueología Subacuática, Cartagena, 1993.

FABIAO, C. y CARVALHO, A., 1990: «Anforas da Lusitania: una perspectiva», en ALARCAO y MAYET, eds. 1990, 38-63.

FARIÑAS, L., FERNÁNDEZ, W. y HESNARD, A., 1977: «Contribution a l'établissement d'une typologie des amphores dites «Dr. 2-4»», en V.V.AA. 1977, 179-206.

FERNÁNDEZ IZQUIERDO, A., 1980: «Estudjo de los restos submarinos en las costas de Castellón», CuadCastellón, 7, 135-195.

- 1982: «Estudio del tráfico marítimo en la costa de Castellón a través de la Arqueología submarina», Saguntum, 17, 113-119.

- 1984: Las ánforas romanas de Valentia y su entorno marítimo, Valencia.

FERNÁNDEZ MIRANDA, M. et al., 1977: Arqueología submarina en Menorca, Madrid. 
FLORIDO, C., 1984: «Anforas prerromanas subibéricas», Habis 15, 419-436.

FORMENTI, A.; HESNARD, A. y TCHERNIA, A., 1978: «Une amphore (Lamboglia 2) content du vin dans l'épave de la Madrague de Giens», Archaeonautica, 2, 95-100.

FURGER-GUNTI, A., 1979: Die Ausgrabungen im Basler Münster, I, Die Spätkeltische und augusteische Zeit (I Jahrundert v. Chr.), Basler Beitrage zur Ur-und Frügeschichte, Band 6, Deredingen-Solothurn.

GARCÍA, M.; SILVESTRE, R. y PÉREZ, C., 1989: «Los fondos marinos», en SANCHIS, J., DIR.: Guía de la naturaleza de la Comunidad Valenciana, Alzira, t. II, 611652.

GARCÍA MENÁRGUEZ, A. 1991: «El embarcadero romano de La Mata (Torrevieja, Alicante)», Alebus, 1, 105-122.

GISBERT, J., 1986: «Dianium», en V.V.AA.: Arqueologia en Alicante, 1976-1986, Alicante, 25-27.

- 1987: «La producció de vi al territori de Dianium durant l'Alt Imperi: el taller d'amphores de la vil-la romana de l'Almadrava (Setla-Mirarrosa-Miraflor), en VV.AA. 1987, 104-118.

GUERRERO, V.M. y ROLDAN, B., 1992: Museo Nacional de Arqueología Maritima. Catálogo de las ánforas prerromanas, Cartagena, 1992.

HAYES, J.W., 1972: Late Roman Pottery, London.

HESNARD, A., 1977: «Note sur un atelier d'amphores Dressel 1 et Dressel 2-4 pres Terracine», MEFRA, 89, 1, 157-168.

HESNARD, A. y LEMOINE, CH., 1981: «Les amphores du Cecube et du Falerne», MEFRA, 93, 1, 243-395.

HERNARD, A. et al., 1989: «Aires de production des gréco-italiques et des Dr. 1», en VV.AA. 1989, 21-65.

JONCHERAY, J.P., 1974: «Etude de l'épave Drammont D, dite des Pelvis, d'aprés les travaux du Groupe d'Etudes Sous-marins de Saint-Raphael», en V.V.AA.: III CIAS, Bordighera.

KEAY, S. J., 1984: Late Roman Amphorae in Western Mediterranean. A typology and economic study: the Catalan evidence, BAR I.S., 196, Oxford.

LAMBOGLIA, N., 1955: «Sulla cronologia delle anfore romane di età republicana, SStLig, XXI, 241-270.

LANCEL, S., 1977: «Fouilles a Carthage, le secteur A», AntAfr, 11.

LAUBENHEIMER, F., 1985: La production des amphores en Gaule Narbonnaise, Besançon.

- 1989: «Les amphores gauloises sous l'Empire: recherches nouvelles sur leur production et leur chronologie», en VV.AA. 1989, 105-138.

- 1990: Les temps des amphores en Gaule, París.

LUZON, J.M., 1973: Excavaciones en Itálica. Estratigrafía en el Pajar de Artillo, EAE, 78, Madrid.

LLOBREGAT, E.A., 1972: Contestania Ibérica, Alicante.

MACEL, C., 1985: Side Scan Sonar; Training Manual, Klein Associates, New Hampshire.

MANACORDA, D., 1977: «Anfore», en V.V.AA.: Ostia IV: le Terme del Nuotatore: scavo dell'ambiente XVI e dell'area XXV, S.M., 23, Roma, 117-254.

MANTILLA, A., 1986: "Las ánforas de época romana en Saguntum», Arse, 21, 565-588.

MAÑA, J.M., 1951: «Sobre tipología de ánforas púnicas», en BELTRÁN, A. (ED.): Crónica del VI Congreso de Arqueología del Sudeste Espanol (Alcoy, 1950), Cartagena, 203-210.

MARTIN, G., 1970: «Las pesquerías romanas en la provincia de Alicante», $P L A V, 10,139$ ss.

MARTIN, G. y SALUDES, J., 1966: «Hallazgos arqueológicos submarinos en la zona del Saler (Valencia)», ArchPrehistLev, XI, 155-170.

MARTIN, G. y SERRES, M.D., 1970: La factoría pesquera de Punta de l'Arenal y otros restos romanos de Jávea (Alicante), TVSIP, 38, Valencia.
MATA, C., 1991: Los Villares (Caudete de las Fuentes, Valencia). Origen y evolución de la cultura ibérica, TVSIP, 88, Valencia.

MAYET, F., 1990a: «Problemes de dénomination», en VV.AA. 1990, 24-28.

- 1990b: «Typologie et chronologie des amphores lusitaniennes», en VV.AA. 1990, 29-35.

MIRO, J., 1984: «Algunas consideraciones sobre las ánforas ibéricas Mañá B 3», Pyrenae, 19-20 (1983-1984), 157-189.

MITCHELL, E., 1985: «Metodi e tecniche di rilevamento subacqueo», VI CIAS (Cartagena, 1982), Madrid, 17-30.

NIETO, F.J., 1984: Introducción a la Arqueología subacuática, Barcelona.

NIETO, F. J. et al., 1989: Excavacions arqueològiques subaquàtiques a Cala Culip I, Girona.

NOLLA, J.M. y NIETO, F.J., 1989: «La importación de ánforas romanas en Cataluña durante el período tardo-republicano», en VV.AA. 1989, 367-392.

NORDSTRÖM, S., 1967: Excavaciones en el poblado ibérico de La Escuera (San Fulgencio, Alicante), Valencia.

OLCINA, M., 1990a: «Costera de la Mar», en GENERALITAT VALENCIANA: Excavacions arqueologiques de salvament a la Comunitat Valenciana 1984-1988: intervencions urbanes, Valencia.

OLCINA, M., 1990b: «Partida de Torres», en GENERALITAT VALENCIANA: Excavacions arqueologiques de salvament a la Comunitat Valenciana 1984-1988: intervencions rurals, Valencia.

PANELLA, C., 1970: «Anfore», en VV.AA.: Ostia II: le Terme del Nuotatore. Scavo dell'ambiente I, Roma.

- 1973: «Appunti su un gruppo di anfore della prime, media e tarda età imperiale», en V.V.AA.: Ostia III: le Terme del Nuotatore: scavo dell'ambiente $V$ e di un saggio nell'area, SM, 21, Roma, 460-633.

- 1981: «La distribuzione e i mercati», en A. GIARDINA y A. SCHIAVONE, eds.: Merci, Mercati e Scambi nel Mediterraneo, Bari, 55-80.

PARKER, A.J., 1977: «Lusitanian amphoras», en VV.AA. 1977, 35 40.

PARKER, A.J. y PRICE, J., 1981: «Spanish exports of the Claudian period: the significance of the Port Vendres II wreck reconsidered», IntJNautA, 10, 221-228.

PASCUAL, R., 1972: «Arqueología submarina en Andalucía (Almería y Granada), Ampurias, 33-34 (1971-1972), 321-324.

- 1977: «Las ánforas de la Layetania», en V.V.AA. 1977, 47-96.

PAVOLINI, C., 1981: «Lucerne in ceramica comune dell'Africa romana (I-IV secolo D.C.)», en VV.AA.: Enciclopedia dell'Arte Antica, Classica e Orientale. Atlante delle forme ceramiche I, Roma, 188-204.

PEACOCK, D. P. S., 1977: «Recent discoveries of Roman amphora kilns in Italy», AntJ. 57, 262-269.

PEACOCK, D. P. S. y WILLIAMS, D.F., 1986: Amphorae and the Roman Economy. An Introductory Guide, New York.

PEARSON, C., 1982: «Side Scan Sonar, record of an XVIIIth Century Spanish merchant vessel in the Gulf of Mexico», IntJNautA, XI-1, 62-63.

PELLICER, M., 1978: «Tipología y cronología de las ánforas prerromanas del Guadalquivir, según el Cerro Macareno (Sevilla)», Habis 9, 365-400.

- 1982: «Las cerámicas del mundo fenicio en el Bajo Guadalquivir. Evolución y cronología según el Cerro Macareno (Sevilla)», Madrider Beiträge-Band 8, Phonizier im Westen, 371-406.

PELLICER, M.; ESCACENA, J.L. y BENDALA, M., 1983: $E l$ Cerro Macareno, EAE, 124, Madrid.

PONSICH, M., 1968: «Alfarerías de la época fenicia y púnico-mauritana en Kouass (Arcila)», PLAV, 4. 
PONSICH, M. y TARRADELL, M., 1965: Garum et industries de salaison dans la Mediterranée occidentale, París.

RABANAL, M.A. y ABASCAL, J.M., 1985: «Inscripciones romanas de la provincia de Alicante», Lucentum IV, 191244.

- 1986: «Dos nuevas inscripciones y algunas correcciones a la epigrafía romana de la provincia de Alicante», Lucentum V, 169174.

RAMON, J., 1981 : lbiza y la circulación de ánforas fenicias y púnicas en el Mediterráneo Occidental, Ibiza.

RIBERA, A, 1982: Las ánforas prerromanas valencianas: fenicias, ibéricas y púnicas, TVSIP, 73, Valencia.

RIBERA, A. y FERNÁNDEZ, A., 1985: «Prospecciones arqueológicas submarinas en la zona del Saler (Valencia)», VI CIAS (Cartagena, 1982), Madrid, 83-91.

RIBERA, A. y RIPOLLÉS, P.P., 1977: «Anforas de Benicarló y su zona costera», CuadCastellón, 4, 159-173.

ROSSELLO, V.M., 1978: «Un variado litoral», en LOPEZ GOMEZ, A. y ROSSELLO, V.M., DIRS.: Geografía de la provincia de Alicante, Alicante.

SALA, F., 1989: «Contribución al estudio del tráfico marítimo antiguo en la costa norte de la provincia de Alicante», Xabiga, 5, 39-64.

SÁNCHEZ, M.J., 1986: «Portus Illicitanus», en VV.AA.: Arqueología en Alicante, 1976-1986, Alicante, 134-136.

- 1991: «La factoría romana de salazón de pescado de Santa Pola (Alicante), en ARANEGUI, C., COORD.: Saguntum y el Mar, Valencia, 117-118.

SÁNCHEZ, M.J., BLASCO, E. y GUARDIOLA, A., 1986: Portus Illicitanus: datos para una síntesis, Alicante.

SÁNCHEZ, M.J.-LLOBREGAD, M. T., 1984: «Estudio preliminar sobre las ánforas romanas del Portus Illicitanus», Lucentum, III, 135-152.

SANMARTí, E., 1985: «Las ánforas romanas del campamento numantino de Peña Redonda (Garray, Soria)», Empúries, 47, $130-161$.

SANTAMARÍA, G., 1961: «Travaux et decouvertes sur l'épave «A» du Cap Drammont», II ClAS (Albenga, 1958), Bordighera, 175-198.

SIMON, J.L., 1990: «Illeta dels Banyets y l'Almadrava, El Campello (Alicante)», en GENERALITAT VALENCIANA: Excavacions arqueologiques de salvament a la Comunitat Valenciana 1984-1988, II, Intervencions rurals, 48-52.

STÖCKLI, W., 1979: Die Grob- und Importkeramik von Manching. Ausgrabungen im Manching, Band 8, Wiesbaden .

TCHERNIA, A., 1971: «Les amphores vinaires de Tarraconaise et leur exportation au debut de l'Empire», ArchEspA, 44, 38-85.
- 1980: «Quelques remarques sur le commerce du vin et les amphores», en J.H. D'ARMS y E.C. KOPF, EDS.: The Seaborne Commerce of Ancient Rome: Studies in Archaeology and History, 305-312.

- 1983: «Italian wine in Gaul at the end of the Republic», en P. GARNSEY, K. HOPKINS y C.R. WHITTAKER, EDS.: Trade in the Ancient Economy, London, 87-104.

- 1986: Le vin de l'Italie romaine, Roma.

TCHERNIA, A. y ZEVI, F., 1972: «Amphores vinaires de Campanie et de Tarraconaise a Ostie», en VV.AA. 1972, 35-67.

THEURET, M.A., 1980: «Side Scan Sonar in Lake Chan plain (Vermont, USA)», IntJNautA IX-1, 35-41.

TORTORELLA, S., 1981: «Ceramica da cucina», e W.AA. Enciclopedia dell'Arte Antica, Classica e Orientale. Atlante delle forme ceramiche I, Roma, 20228.

ULBERT, G., 1959: Die Römischen Donau-Kastelle Aislingen und Burghöfe, Limesforschungen. Studien zur Organisation der Römischen Reichsgrenze an Rhein und Donau, Band I, Berlín.

VAN DER WERFF, J.H., 1978: «Amphores de tradition punique a Uzita», Babesch, 52-53, 171-200.

VV.AA., 1972: Recherches sur les amphores romaines, Actas del Coloquio de Roma (1971), Roma.

VV.AA., 1977: Méthodes classiques et méthodes formelle dans l'étude des amphores, Actes du Colloque de Rom (1974), Roma.

VV.AA., 1983: Terra sigillata hispánica, Monografías del Museo Arqueológico Nacional 2, Madrid.

VV.AA., 1987: Actes del I Col-loqui d'Arqueologia Romana: el Vi a l'Antiguitat. Economia, Producció i Comerç al Mediterrani Occidental, Badalona.

W.AA., 1989: Amphores Romaines et Historie Economique. Dix Ans de Recherche, Actes du Colloque de Sienne (1986), Roma.

WAGNER, J., 1978: «El yacimiento submarino de Torre-la Sal (Cabanes, Castellón), CuadCastellón, 5, 305-331.

WIDEMANN, F., LAUBENHEIMER, F. y LEBLANC, J. 1979: «Amphorae workshops in western Narbonensis. The non-resolution space problem», en VV.AA.: XIX Symposium of Archaeometry and Archaeological Prospection, London, 57-71.

WIDEMANN, F. et al. 1978: «Analytical and typological study of gallo-roman workshops producing amphorae in the area of Narbonne», Archaeophysiko, 10, Bonn, 317341.

WILL, E.L., 1979: «The Sestius amphoras: a reappraisal» JFieldA, 6, 339-350.

- 1982: «Greco-italic amphoras», Hesperia, 52, 338-356.

ZEVI, F., 1966: «Appunti sulle anfore romane, $\mathrm{ArchCl}$, 18-2,207247. 